Article

\title{
Interface and Interphase in Polymer Nanocomposites with Bare and Core-Shell Gold Nanoparticles
}

\author{
Albert J. Power ${ }^{1,2, *}$, Ioannis N. Remediakis ${ }^{3,4}$ (D) and Vagelis Harmandaris $1,2,5, *$ (D) \\ 1 Department of Mathematics and Applied Mathematics, University of Crete, \\ GR-71409 Heraklion, Crete, Greece \\ 2 Institute of Applied and Computational Mathematics (IACM), \\ Foundation for Research and Technology Hellas (FORTH), GR-71110 Heraklion, Crete, Greece \\ 3 Department of Materials Science and Technology, University of Crete, GR-71003 Heraklion, Crete, Greece; \\ remed@materials.uoc.gr \\ 4 Institute of Electronic Structure and Laser, (IESL), Foundation for Research and Technology Hellas (FORTH), \\ GR-71110 Heraklion, Crete, Greece \\ 5 Computation-Based Science and Technology Research Center, The Cyprus Institute, Nicosia 2121, Cyprus \\ * Correspondence: ajpower@math.uoc.gr (A.J.P.); harman@uoc.gr (V.H.); Tel.: +30-2810393735 (V.H.)
}

check for

updates

Citation: Power, A.J.; Remediakis, I.N.; Harmandaris, V. Interface and Interphase in Polymer

Nanocomposites with Bare and

Core-Shell Gold Nanoparticles.

Polymers 2021, 13, 541.

https://doi.org/10.3390/polym13040541

Academic Editors:

Argyrios Karatrantos and

Martin Kroger

Received: 30 November 2020

Accepted: 8 February 2021

Published: 12 February 2021

Publisher's Note: MDPI stays neutral with regard to jurisdictional claims in published maps and institutional affiliations.

Copyright: (c) 2021 by the authors. Licensee MDPI, Basel, Switzerland. This article is an open access article distributed under the terms and conditions of the Creative Commons Attribution (CC BY) license (https:/ / creativecommons.org/licenses/by/ $4.0 /)$.

\begin{abstract}
Metal nanoparticles are used to modify/enhance the properties of a polymer matrix for a broad range of applications in bio-nanotechnology. Here, we study the properties of polymer/gold nanoparticle (NP) nanocomposites through atomistic molecular dynamics, MD, simulations. We probe the structural, conformational and dynamical properties of polymer chains at the vicinity of a gold (Au) NP and a functionalized (core/shell) Au NP, and compare them against the behavior of bulk polyethylene (PE). The bare Au NPs were constructed via a systematic methodology starting from ab-initio calculations and an atomistic Wulff construction algorithm resulting in the crystal shape with the minimum surface energy. For the functionalized NPs the interactions between gold atoms and chemically adsorbed functional groups change their shape. As a model polymer matrix we consider polyethylene of different molecular lengths, from the oligomer to unentangled Rouse like systems. The PE/Au interaction is parametrized via DFT calculations. By computing the different properties the concept of the interface, and the interphase as well, in polymer nanocomposites with metal NPs are critically examined. Results concerning polymer density profiles, bond order parameter, segmental and terminal dynamics show clearly that the size of the interface/interphase, depends on the actual property under study. In addition, the anchored polymeric chains change the behavior/properties, and especially the chain density profile and the dynamics, of the polymer chain at the vicinity of the Au NP.
\end{abstract}

Keywords: molecular dynamics simulations; gold; nanoparticles; core-shell; grafted; structural and dynamical properties of polymers; polyethylene

\section{Introduction}

The study of polymer-based hybrid materials is a field of immense interest as it involves a broad spectrum of systems, applications, and spatiotemporal scales. On polymer/solid nanostructured systems in particular, the solid phase can strongly modify the properties of the entire hybrid system, such as its mechanical and electrical ones, as well as its dynamical/rheological behavior [1-7]. Therefore, the investigation of model polymer/solid interfacial systems, at the molecular level, is an intense research area, since such interfaces play a crucial role on the behavior of polymer-based systems with important technological applications, including for example polymer nanocomposites, polymer coatings, lubricants and thin films [8-12]. Examples include the modification of the electrochemical behavior [13] and the amelioration of the thermal degradation of the nanocomposites [14]. Moreover, there have been reports of enhancement of hardness, solvent resistance and 
glossiness of nanocomposites [15]. The improvement of the tensile strengths of nanocomposite films [16] and the enhancement of the interfacial adhesion between nanoparticle and polymer matrix are also very important [17]. Furthermore, nanoparticles modify the mechanical properties of a polymer matrix [18,19].

From the broad family of polymer nanocomposites (PNCs) here we focus on systems with (bare and core/shell) metal nanoparticles (NPs). Such systems have been used in the recent past in bio-nano-technology for biomedical utilization, including antibacterials [20], antimicrobials [21,22], biosensors [23], cancer treatment [24] and biomedical tissue engineering $[25,26]$. Their usage is also explored in other technological applications involving catalytic devices, in the textile industry and in food packaging [27-32]. In particular, polymer systems with dispersed gold (Au) NPs, or core/shell gold NPs, have been extensively studied due to their exceptional properties, such as biocompatibility, tunable conductivity and catalytic properties. Au nanoparticles of few nanometers (1 to $100 \mathrm{~nm}$ ) have a great surface/volume ratio and that enables their surface to be coated with many molecules (including therapeutics and targeting agents). Moreover, they are among the most stable of metal nanoparticles and they also provide a stable immobilization platform of the molecules while their reactivity is conserved. Their properties include colloidal stability and the ability to be conjugated with ease with biological molecules. Applications of polymer nanocomposites with Au NPs span many scientific fields, such as medicine [33] biotechnology [34], catalysis [35], and electronics [36]. In all these applications, the shape of Au nanoparticles has a key role in every aspect of their functionality, from sensing [37] and biolabeling applications [38] to plasmonics [39], photonics [40] and fuel cells [41]. Additional technological areas in which gold nanoparticles have been used include: the storage of energy [42], the delivery of molecules into cells [33,43], use as a heat source [44], as sensors [45-47], labeling [48,49], Light Emitting Diode (LED) applications [50], optical and electronic applications [39], drug delivery vehicles [51,52] and in the field of catalysis [35,53-55].

Besides experiments [56-64], molecular simulations have been used to study the properties of polymer-based complex materials [65-71], including atomistic molecular dynamics (MD) [3,72-76], dynamic Monte Carlo simulations (MCMD) [77-79], self-consistent field theory (SCFT) and density functional theory (DFT) [80], dissipative particle dynamics (DPD) [81], coarse-grained (CG) MD simulations [82-85] and stochastic dynamics simulations [86].

We should note that polymer/NP hybrid system have been already simulated in the past, mainly via qualitative CG bead spring models, but atomistic simulations as well. However, limited are the atomistic works including metals, and especially Au, NPs. Given the important role of the actual chemistry on the polymer/NP interaction and on the overall properties of the hybrid material, quantitative atomistic simulations of specific systems can be valuable tools, complementary to experiments, to provide a fundamental study of specific systems.

Here we study via atomistic simulations polymer nanocomposites with bare and grafted Au NPs; the latter were constructed in their minimum energy configuration, via the Wulff method, whereas the PE/Au interaction is derived via DFT calculations. We further examined and compared hybrid systems with bare and grafted Au NPs, focusing on the PE/Au interphase. Moreover, properties of polymer chains are studied as a function of: (a) size of the Au NP, (b) MWs of the polymer matrix and (c) lengths of the anchored polymeric chains.

It is now acknowledged that the behavior of polymer chains close to a polymer/solid interface is different from the behavior of the bulk [87-92]. For such systems, an interphase between the substrate and the bulk phase of the polymer is postulated, and the width of this interphase layer has been the focus of many studies. For example, it has been observed that segmental packing and orientation return to bulk values within just a few segment lengths from the surface and chain properties reached the bulk values after a few 1-2 times the radius of gyration $R_{g}$ using atomistic and systematic coarse-grained models [88,93], 
or bead-spring models $[94,95]$. In addition, concerning the segmental dynamics of the macromolecules, relaxation times of segments at the vicinity of a solid surface strongly depend on the strength of the polymer/surface interactions $[89,96]$. For polymer chains supported by a solid substrate the size of the interface or interphase depends on the actual property under study [88].

Furthermore, coarse-grained MD, Monte Carlo MD and atomistic MD simulations have been used to examine the viscoelastic behavior and the dispersion-aggregation transition of NPs in polymer nanocomposites with polymer-grafted nanoparticles systems [97-101], to compute the mean square displacement and the mean relaxation time of various intramolecular vectors [102], the structural properties and the mass density profiles of polymers brushes (grafted) [67,78]. Moreover, several studies have investigated the polymer's structure, rheological properties and the shearing of the polymer between two gold surfaces, using MD simulations [103-105]. Finally, the mass density profiles, the mean square displacement, the end to end distance and the radius of gyration of polymer chains for PNCs with gold nanoparticle have been examined through MD simulations as well [73].

Despite the above works, the study of the polymer/metal NP interface, and interphase as well, by predicting quantitatively the properties of polymer chains of specific polymer nanocomposites, using realistic atomistic models for both polymer matrix and the $\mathrm{Au}$ NP is still a challenging problem. The main goal of this work is to provide a detailed investigation of polymer nanocomposites with dispersed gold nanoparticles and core/shell gold nanoparticles, at the molecular level through detailed MD simulations. As model polymer we consider polyethylene (PE). Bulk PE and PE-based nanocomposite materials are among the most widely used polymers in industry, and have been studied in depth during the recent years through experiments [106-108] and simulations [96,109,110]. The $\mathrm{Au}$ NPs and the functionalized Au NPs are made with Wulff construction derived directly from density functional theory (DFT) calculations [111,112] in order to obtain model Au NPs with the minimum surface free energy, i.e., at thermodynamic equilibrium.

In the next section the model, the simulation method and the analysis techniques that we have used are described. Our results, divided in subsections, are presented in Section 3. Finally, a summary and the conclusions of the current study are presented in Section 4.

\section{Model and Simulation Method}

We study PE nanocomposites with bare Au NPs and with functionalized, with short PE chains, (core/shell) NPs. The model gold nanoparticles, were generated using an atomistic Wulff construction algorithm [111,112]. The grafting of the gold nanoparticles was accomplished by using anchored polyethylene chains. In all cases the temperature is $450 \mathrm{~K}$, above the melting temperature of PE. Ten (10) different model systems are considered, involving two different monodisperse PE matrices (Table 1); one consists of chains with 22 monomers $(\mathrm{MW}=310 \mathrm{gr} / \mathrm{mol})$ and the other one with 100 monomers (MW = $1400 \mathrm{gr} / \mathrm{mol})[109,110,113]$. Two different gold NP sizes with Wulff construction were modeled [111,112]: one with diameter of $25 \AA$ and one with $50 \AA$. Systems with the same polymer matrix but a different nanoparticle are also studied. Both of the grafted Au nanoparticles have a diameter of $5 \mathrm{~nm}$ and 53 grafted polyethylene chains. The first one has 20 monomers per chain and the other one 62 monomers per chain. The grafting density is 0.67 chains per square $\mathrm{nm}$. That value has been used in several experimental studies of different PNCs [114]. The equilibrium shape of nanoparticles is a polyhedron that is derived through the Wulff construction. Small nanoparticles often deviate from this thermodynamically stable equilibrium shape: for example, at small diameters, an edge length might be smaller than the atom diameter. For $\mathrm{Au}$, the smallest nanoparticle that has same polyhedral shape as the Wulff construction has a diameter of about $2.5 \mathrm{~nm}$ for both bare- and thiol-covered nanoparticles [111,112]. For comparison, we also considered larger nanoparticles with diameters around $5 \mathrm{~nm}$. 
Table 1. Details of the simulated model systems.

\begin{tabular}{|c|c|c|c|c|c|c|c|}
\hline Name & $\begin{array}{c}\text { Au NP } \\
\text { Diameter }\end{array}$ & Au Atoms & $\begin{array}{l}\text { Free PE } \\
\text { Chains }\end{array}$ & $\begin{array}{l}\mathrm{Au} / \mathrm{PE} \\
w / w \%\end{array}$ & $\mathrm{Au} / \mathrm{PE} v / v \%$ & $\begin{array}{c}\text { Grafted PE } \\
\text { Chains }\end{array}$ & $\begin{array}{l}\text { Grafted PE } \\
\text { Mers/Chain }\end{array}$ \\
\hline PE100/Au2 & $25.1 \AA$ & 459 & 1200 & 4.9 & 0.2 & - & - \\
\hline PE100/Au5 & $50.2 \AA$ & 3101 & 1200 & 37.6 & 1.7 & - & - \\
\hline PE100/Au5/g20 & $50.4 \AA$ & 2461 & 1200 & 29.7 & 1.7 & 53 & 20 \\
\hline PE100/Au5/g62 & $50.4 \AA$ & 2461 & 1200 & 29.7 & 1.7 & 53 & 62 \\
\hline PE100 & - & - & 240 & - & - & - & - \\
\hline PE22/Au2 & $25.1 \AA$ & 459 & 5040 & 5.8 & 0.4 & - & - \\
\hline PE22/Au5 & $50.2 \AA$ & 3101 & 5040 & 38.8 & 1.6 & - & - \\
\hline PE22/Au5/g20 & $50.4 \AA$ & 2461 & 5040 & 30.8 & 1.6 & 53 & 20 \\
\hline PE22/Au5/g62 & $50.4 \AA$ & 2461 & 5040 & 30.8 & 1.6 & 53 & 62 \\
\hline PE22 & - & - & 420 & - & - & - & - \\
\hline
\end{tabular}

More details for all systems are presented in Table 1. Typical snapshots of the model $\mathrm{PE} / \mathrm{Au}$ (bare and core/shell) NP systems are shown in Figure 1 and in Appendix A Figure A1. A video (Supplementary Materials) from our MD simulation of hybrid polyethylene/ grafted gold nanoparticle at $450 \mathrm{~K}$ is available online at www.mdpi.com/2073-4360/13/4/541/s1, Video S1: PE-grafted AuNP.

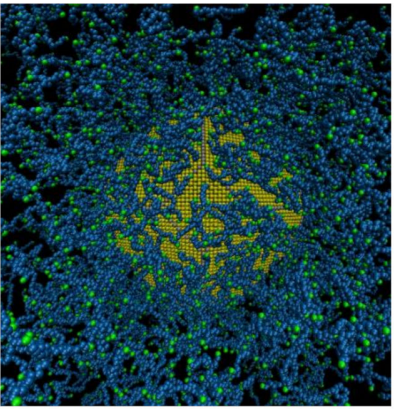

(a)

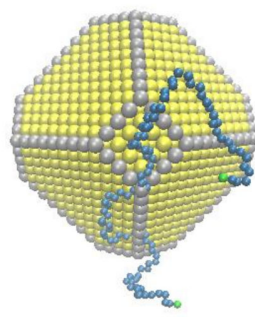

(b)

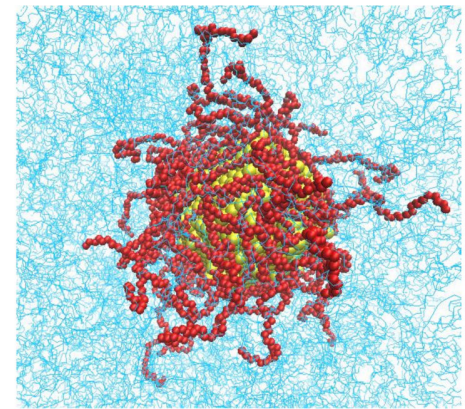

(c)

Figure 1. Snapshots from the model systems: (a) The PE22/Au5 hybrid system. In yellow is the $\mathrm{Au}$, in blue are the $\mathrm{CH}_{2}$ monomers and in green are the $\mathrm{CH}_{3}$ monomers. (b) $\mathrm{Au} \mathrm{NP}$, of $d=5.02 \mathrm{~nm}$ (in yellow are the $\mathrm{Au}$ atoms and in grey the edge $\mathrm{Au}$ atoms), and a PE 100 mer chain. (c) The $\mathrm{PE} 100 / \mathrm{Au} 5 / \mathrm{g} 62$ hybrid system. In blue are the free $\mathrm{CH}_{2}$ and the free $\mathrm{CH}_{3}$ monomers. In red are the grafted $\mathrm{CH}_{2}$ and $\mathrm{CH}_{3}$ monomers.

We used the LAMMPS package [115] to perform Molecular Dynamics (MD) simulations in the isothermal-isobaric (NPT) statistical ensemble. We kept the pressure constant at $P=1 \mathrm{~atm}$ by using Nosé Hoover barostat. To keep the temperature at $T=450 \mathrm{~K}$ we used the Nosé Hoover thermostat. Periodic boundary conditions in all three dimensions were used, whereas the integration time step was $1.0 \mathrm{fs}$. Furthermore, we used a united atom model to represent the polyethylene. In this case, each methylene $\mathrm{CH}_{2}$ and methyl $\mathrm{CH}_{3}$ group represented as a single Van der Waals interacting site. Harmonic potential was used to describe the polyethylene bonds and angles whereas the OPLS force field (Appendix A Table A1) was used to describe the polyethylene dihedrals. For the Van der Waals interactions between the PE-PE (Appendix A Table A2) we used a spherically truncated 6-12 Lennard-Jones potential with cutoff distance $R_{\mathrm{c}}=10 \AA$ [109]. The first gold nanoparticle with Wulff construction has 459 atoms with $2.51 \mathrm{~nm}$ diameter and the second has 3101 atoms with $5.02 \mathrm{~nm}$ diameter [111,112]. The interaction between the $\mathrm{Au}$ and PE is described via a Morse potential, which is taken from the literature and is based 
on detailed DFT calculations $[88,93,116]$. This potential is parametrized in order to describe with accuracy extensive DFT data regarding the adsorption energy of the ethylene on the $\mathrm{Au}$ surface as a function of distance for several different adsorption sites.

For the core/shell Au NP systems the S atoms were placed on the Au NPs in their minimum energy positions as computed from the DFT calculations [116]. Interactions between the $\mathrm{S}$ and $\mathrm{CH}_{\mathrm{x}}$ groups of $\mathrm{PE}$ were modeled via a 6-12 Lennard-Jones potential with cutoff distance $R_{\mathrm{c}}=10 \AA$ (see Table A2 in Appendix A). For the $\mathrm{S}-\mathrm{CH}_{2}-\mathrm{CH}_{2}-\mathrm{CH}_{2}$ dihedral angle interactions the OPLS force field was used. The entire atomistic force field is given in Tables A1 and A2 of the Appendix A. Tail corrections were applied to both energy and pressure. For the non-bonded interactions between PE-PE monomers, the LorentzBerthelot rules were used. The gold nanoparticles are frozen during the duration of the MD runs. This is not expected to be a crude assumption since the Au NPs are very stable under conditions (temperature and pressure) similar to those of the current simulations.

\subsection{Shape of $A u$ NPs}

Gold nanoparticles can be found in nature in various shapes. Here we consider their "equilibrium" conditions, i.e., the shape with the minimum surface energy $[53,54,112,117]$. At the limit of very large nanoparticles (thermodynamic limit), the shape is a polyhedron. The faces of this polyhedron are parallel to different $(h k l)$ orientations of the crystal lattice. The total surface energy, $F$, of the nanoparticle, given by,

$$
F=\sum_{h k l} A_{h k l} \gamma_{h k l}
$$

is minimum, where the summation is over all faces of the nanoparticle. $A_{h k l}$ is the sum of areas of all faces that are parallel to the $(h k l)$ crystal plane and $\gamma_{h k l}$ is the surface tension of the material (energy per unit area) when its surface is cleaved parallel to the $(h k l)$ plane of the crystal.

G. Wulff proposed that the shape that minimizes surface energy in Equation (1) is such that the distance of each face from the center is proportional to the surface tension of the respective $(h k l)$ surface [118]:

$$
d_{h k l} \sim \gamma_{h k l}
$$

The surface tensions, $\gamma_{h k l}$, can be calculated by simulating thick enough slabs of the material with faces parallel to the $(h k l)$ crystal plane. Typically, the total energy is calculated using quantum-mechanical calculations, such as Density-Functional Theory (DFT). The equilibrium shapes of gold nanoparticles used in the present work were obtained by coupling extensive DFT calculations to Wulff constructions [111,112]. Through this hybrid methodology atomistic models of nanoparticles were constructed with diameters up to several tenths of a nanometer [118-120].

Different $(h k l)$ planes bind differently to functional groups due to the presence of different atomic arrangements. As a result, the energies $\gamma_{h k l}$ depend not only on the orientation $(h k l)$ but also on the binding energy and the grafting density on the surface. The binding energies can be calculated using DFT [117]. This multi-scale scheme has been used to analyze shapes of nanoparticles of different materials, including $\mathrm{SiO}_{2}$ [120], $\mathrm{Au}$ with adsorbed $\mathrm{CO}$ [112], $\mathrm{Ag}$ [121], and $\mathrm{Pt}$ in $\mathrm{HCl}$ [122].

Here, we use the nanoparticles generated with the method used in Ref. [111]. In that work, DFT and Wulff construction was used to calculate equilibrium shape of gold with adsorbed alkanethiols. The resulting shape resembled a deltoidal icositetrahedron with twenty-four faces oriented towards (211). In the absence of alkanethiols, the equilibrium shape was a truncated octahedron, with eight (111) faces and six (100) faces. Smaller nanoparticles usually have small deviations from the Wulff equilibrium shape as the smallest faces might have areas comparable to the atom cross-sections. 


\subsection{Generation and Equilibration of Model Systems}

Generation and equilibration of model polymer nanocomposites is not a trivial issue. Below we describe shortly the procedure followed in order to obtain the model PE/Au nanocomposites:

(a) First, in order to obtain initial PE/grafted Au configurations, we added the anchors to the Au surface randomly by using a Monte Carlo algorithm in suitable positions according to the shape of the Au and taking into account the absorption sites of sulfur in the DFT calculations of alkanethiols adsorbed on Au.

(b) Second, we equilibrate the hybrid system through energy minimization and long simulation runs. Energy minimization of the core/shell system was performed followed by MD simulation runs up to $10 \mathrm{~ns}$ in the NVT ensemble. Then, the Au nanoparticle, grafted or not, was placed at a close distance (about $0.5 \mathrm{~nm}$ ) to several well-equilibrated polymer samples [109].

(c) The final step of our "equilibration protocol" involves the execution of long MD simulations, of the order of $30 \mathrm{~ns}$. Throughout this time we monitored the motion of the whole hybrid system. Our simulations run times were much higher than the relaxation times of the chains [109].

We used various criteria to ensure equilibration of the model systems. We computed the time evolution of the radius of gyration, $R_{\mathrm{g}}$, values and checked the de-correlation of the end to end vector (ACF) of polymer chains. Furthermore, we performed several (3-5) different simulations by following the exact same procedure but starting with different initial configurations and we end with the same results.

Starting from the well equilibrated atomistic PE/Au configurations, we executed production runs for times up to $100 \mathrm{~ns}$. We saved many thousands of PE/Au NP configurations. We used these configurations to estimate the properties of the whole hybrid systems and for the detailed analysis of PE/NP interfaces. Note, that the above methodology can be expanded to provide well equilibrated atomistic configurations of other polymer/core shell NP nanocomposites as well.

\subsection{Analysis Method}

Our main goal is to study the spatial and dynamical heterogeneities of model hybrid polymer/nanoparticle systems in a detailed way at the molecular level. Consequently, we examined properties of the polymer chains as a function of the distance from the $\mathrm{Au}$ NP $[96,119]$. This analysis was achieved by forming spherical shells of increasing radius (i.e., increasing distances form the Au NP), for each saved configuration, along radial distances from the center of mass of the gold NP (see Figure 2).

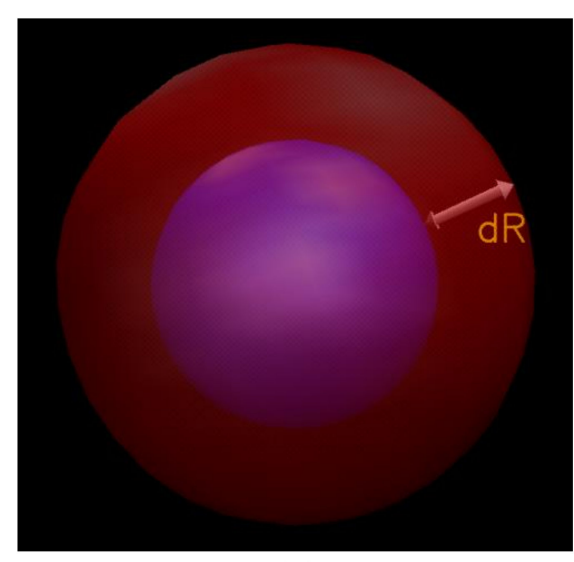

(a)

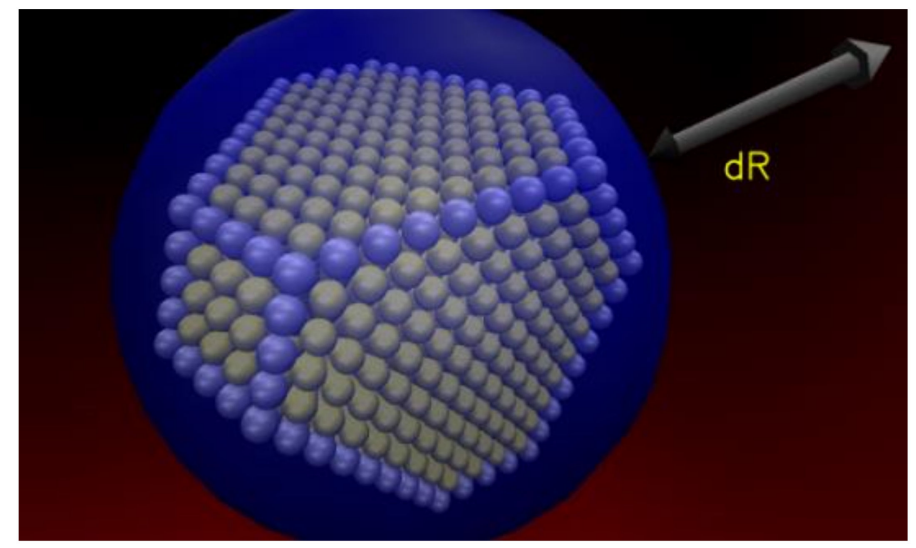

(b)

Figure 2. (a) A sketch of the analysis scheme in spherical shells. (b) Inside view of the Figure 2a. 
Subsequently, we calculated the mass density profiles based on the above radial distance analysis. The thickness of the spherical shells involved was $1 \AA$. To calculate the second rank bond order parameter we used the same binning (thickness of spherical shells). To calculate the orientational and translational dynamical properties in segmental level and to improve statistics we used spherical shells of a thickness of around 5-10. . For the calculation of the mean squared displacement we used spherical shells of a thickness of around 15-20 A. We chose the binning size for the computation of each specific property based on an optimal combination of detailed information and improved statistics. Furthermore, for the calculation of the density of $\mathrm{PE}$ as a function of the distance from the nanoparticle, the mass (computed via the number) of PE atoms within each spherical shell was divided by its volume.

\section{Results}

\subsection{Structural Properties}

We start the analysis of the simulation results by investigating the structural properties of the model atomistic PE/Au nanocomposites.

\subsubsection{Density Profiles}

The analysis of the PE/Au model nanocomposites was commenced by calculating the mass monomer density profile of the polymer (PE) chains as a function of the distance from the gold NP. All systems consisting of polyethylene matrices of 100 mers per chain whose average density profiles we calculated for the center of mass of the monomers, $\rho(r)$, are shown in Figure 3 and all systems consisting of PE matrices of 22 mers per chain are shown in Appendix A Figure A2.

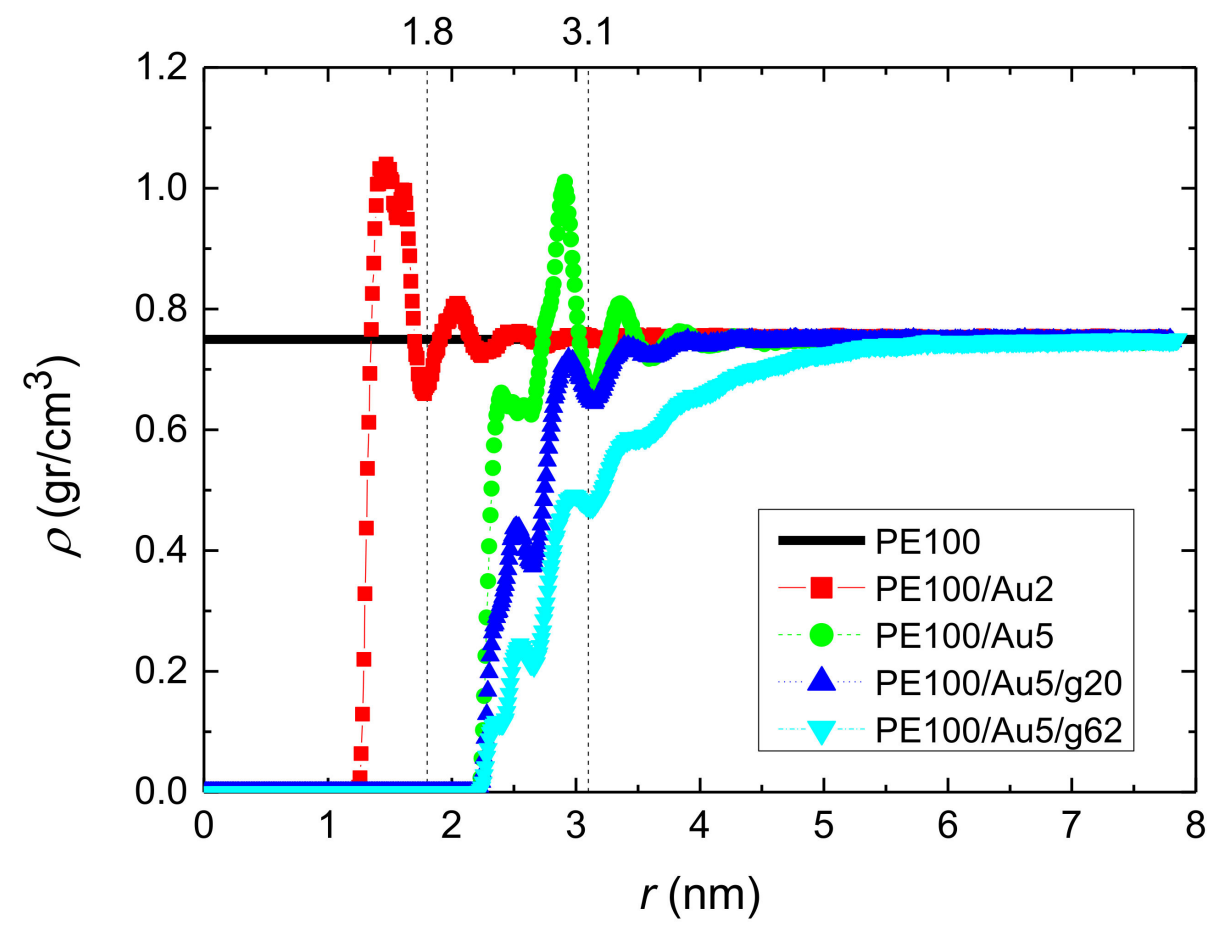

Figure 3. Mass monomer density profiles of polyethylene as a function of $r$ (distance from the center of the gold NP) for the systems: PE100, PE100/Au2, PE100/Au5, PE100/Au5/g20 and PE100/Au5/g62.

In Figure 3, the polymer mass at each spherical shell has been divided by the total volume of the shell. Far from the Au NP, all curves reach/approach the bulk density value $\left(\rho=0.75 \mathrm{gr} / \mathrm{cm}^{3}\right)$, though at different distances due to the different Au NP sizes. PE100/Au2 and PE100/Au5 systems exhibit the same behavior: a peak of rather similar 
height (but larger than the bulk value) is observed at a distance/radius of about $1.3 \mathrm{~nm}$ and $1.8 \mathrm{~nm}$ respectively, which denotes the attraction of the polymer atoms from the gold $\mathrm{NP}$ at short distances, due to vdW forces, while at longer distances the bulk density is attained. In the core/shell Au NP systems (PE100/Au5/g20 and PE100/Au5/g62), only few polyethylene chains can penetrate the anchors and reach the gold surface. We observe a similar behavior for the systems consisting of PE matrices of 22 mers per chain although in this case the average density is lower than that of the systems consisting of PE matrices of 100 mers per chain. The above values are in very good agreement with experimental data for bulk PE chains [123].

For the core/shell NP systems, the density profile can be decomposed to free polyethylene chains and grafted polyethylene chains. As free PE chains we consider the PE matrix and as grafted PE chains, the grafted chains that are anchored on the gold NP. In Figure 4, the total PE density profiles is shown as well as its decomposition in "free" and "grafted" chains. We observe that the density values for the free polyethylene chains are lower than the corresponding bulk value close to the surface due to the nanoparticle's anchors, which do not allow the interpenetration. However, the NP with short anchors allows more free PE chains to reach close to the surface compared to the case of long anchors NP. On the other hand for the grafted polyethylene chains (i.e., PE100/Au5/g20 and PE100/Au5/g62 systems) we observe a peak close to the Au NP due to the attraction from the surface. This peak is more pronounced for the case of $\mathrm{PE} 100 / \mathrm{Au} 5 / \mathrm{g} 62$ system due to the longer anchors. Moreover, the extension of anchors is up to $35 \AA$ and up to $55 \AA$ for the PE100/Au5/g20 and PE100/Au5/g62 systems respectively. Therefore, the corresponding bulk values are attained at these distances, as is observed in the density profiles of the total density curves (sum of free and grafted polyethylene chains). A similar behavior is observed for the PE22/Au2, PE22/Au5, PE22/Au5/g20 and PE22/Au5/g62 systems however in this case the average density is lower than that of the systems consisting of PE matrices of 100 mers per chain.

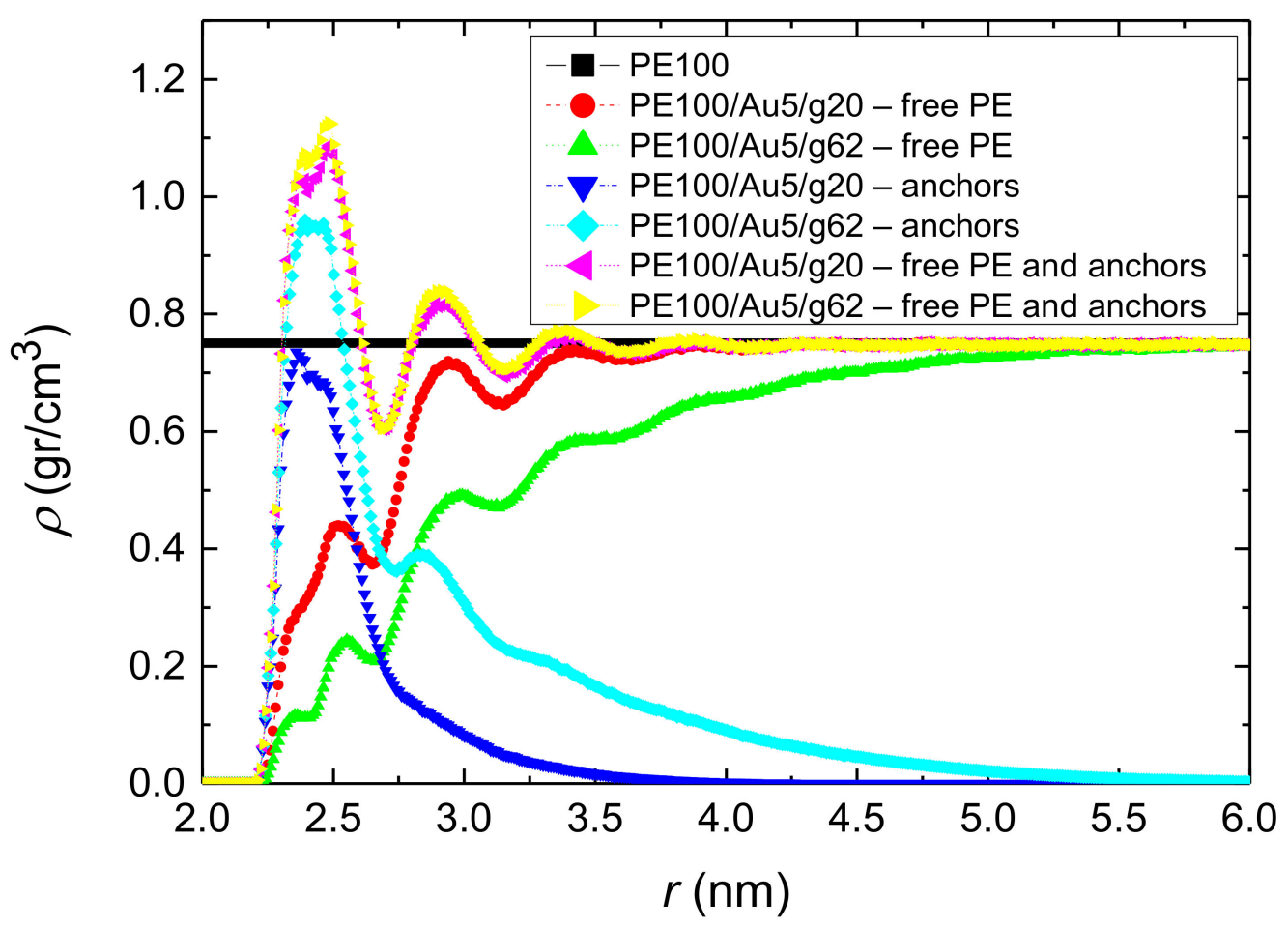

Figure 4. Mass monomer density profiles of polyethylene as a function of $r$ (distance from the center of the gold NP). Au5/g20 and PE100/Au5/g62 systems. The density profile was decomposed to free polyethylene chains and grafted polyethylene chains. 


\subsubsection{Structure of PE Chains}

Bellow we examine the orientation of the polymer chains close to the gold NP in the segmental level, through the $v^{1-3}$ vector, which connects two non-consecutive carbon atoms. The segmental orientation is quantified via the second rank bond order parameter $[12,124]$ defined as:

$$
S_{1-3}=\frac{3}{2}\left\langle\cos ^{2} \theta\right\rangle-\frac{1}{2}
$$

where $\theta$ is the angle between a vector which is defined along the chain (here the $v^{1-3}$ one) and one that connects the center of the gold NP with the midpoint of the above $\left(v^{1-3}\right)$ vector (see Figure A3 in Appendix A), and whereas brackets \langle\rangle denote statistical average. $S_{1-3}$ limiting values of $-0.5,0.0$, and 1.0 correspond to perfectly parallel, random, and perpendicular vector orientations relative to the Au NP, respectively. For the limiting values we assume smooth plain surface.

The bond order parameter of $v^{1-3}$ for all systems with PE matrices consisting of 100 mers per chain is depicted in Figure 5. In all cases there is an obvious tendency of the segments of the polymer chain for an almost parallel orientation relative to the Au NP surface at short distances which is gradually randomized the further the distance. There is a decrease of the bond order parameter of the PE segments closest to the Au NP and the minimum values are about -0.4 for all hybrid systems. The same behavior is observed for the other model systems studied here as well.

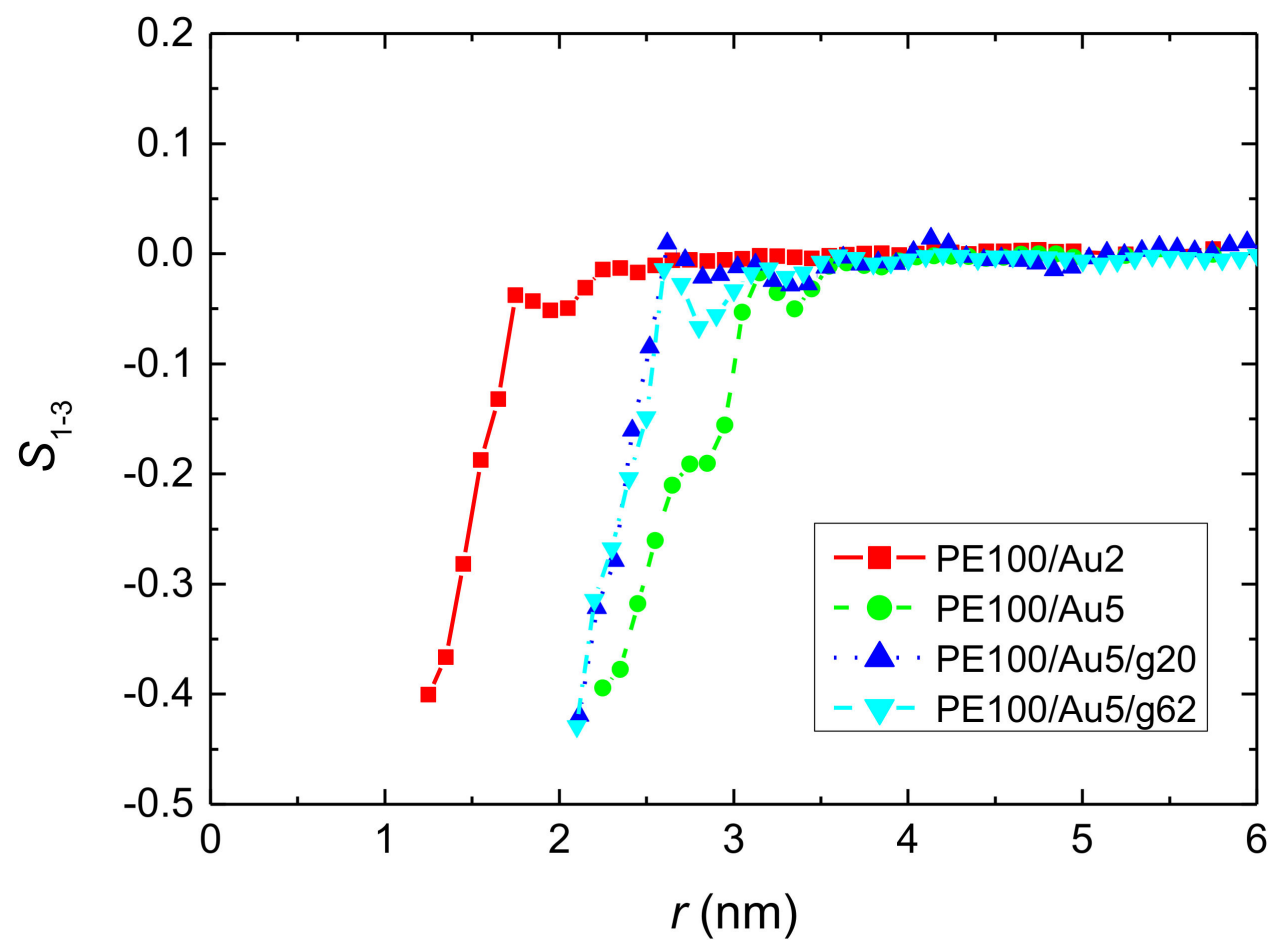

Figure 5. Second rank bond order parameter $S_{1-3}$ of polyethylene chains for $v^{1-3}$ vector, as a function of distance from the center of the Au NP, $r$, for all PE/Au systems with PE matrices consisting of 100 mers per chain.

To further analyze the PE chain conformations at the segmental level we probe the distribution of the torsional (dihedral) angles, $P_{\text {dih }}$, of polymer chains at different distances from the gold NP. Results about the dihedral angle distributions of the PE chains are shown in Figure 6a for the PE100/Au2 system ("trans" corresponds to $0^{\circ}$, "gauche-" and "gauche+ $+^{\prime \prime}$ to $-60^{\circ}$ and $+60^{\circ}$ respectively and "cis" to $180^{\circ}$ degrees). For the first adsorption layer, defined via the first minimum in the density profile ( $0-30 \AA$, see Figure 3$)$, a nonnegligible enhancement of the trans states with a consequent reduction of the gauche ones 
is observed for PE22/Au2, PE22/Au5, PE100/Au2 and PE100/Au5 systems compared to the bulk case (Figure $6 \mathrm{~b}$ ). This observation reflects the more ordered PE chains close to the gold NP. Enhancement of "trans" population would be expected to affect the crystallinity of PE chains as well as the mechanical properties of the hybrid system. Such a behavior has been observed for PE adsorbed on planar carbon-based surfaces, such as graphite or graphene, where the structure of PE commensurate to the underlying crystal structure of the substrate $[3,96,125,126]$. Here the enhancement of "trans" population is rather weak.

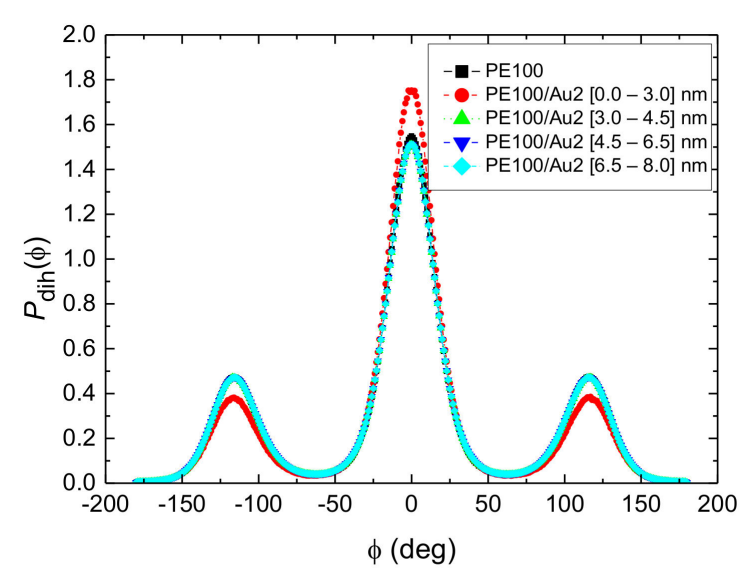

(a)

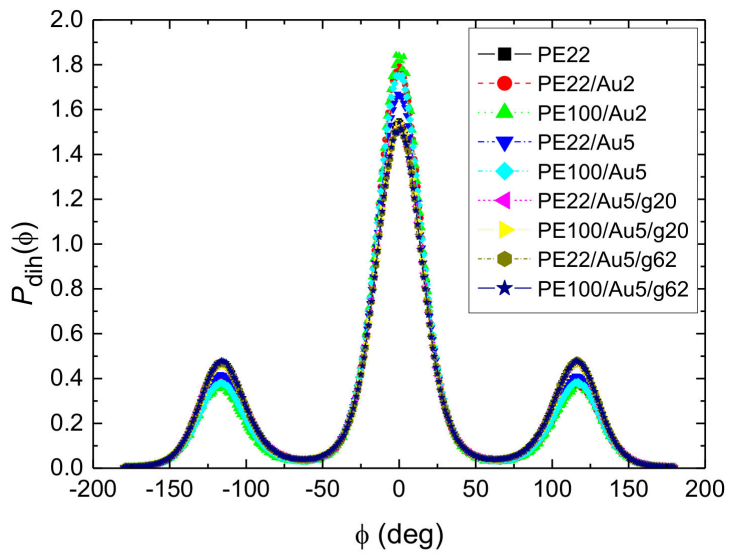

(b)

Figure 6. (a) Torsional angles distribution of PE chains for various distances from the center of the gold NP for the PE100/Au2 system and the corresponding PE bulk curve. (b) Torsional angles distributions of all model systems for PE chains belonging in the first adsorbed layer, i.e., being closer to the Au NP. The corresponding curves for bulk PE are also shown.

Concerning the system with the functionalized Au NPs (PE22/Au5/g20, PE22/Au5/g62, $\mathrm{PE} 100 / \mathrm{Au} 5 / \mathrm{g} 20$ and PE100/Au5/g62) no differentiation in the torsional angle distributions is detected. Short anchors as in PE100/Au5/g20 and PE22/Au5/g20 systems are enough to make the dihedral distribution peak to disappear. For the most distant adsorption layer (i.e., bulk region), the curves are completely identical to each other and to the corresponding bulk one.

In addition, the radius of gyration $\left(R_{\mathrm{g}}\right)$ for the PE was calculated and found approximately $6 \AA$ in the systems consisting of 22 monomers per chain (Appendix A Figure A4) and approximately $16 \AA$ in the systems consisting of 100 monomers per chain (Appendix $\mathrm{A}$ Figure A5). These values are very close to the experimental data [127]. Moreover, we observed a small increment, about $5 \%$, of the $R_{\mathrm{g}}$ close to the surface area, as we expected. Such perturbation of the $R_{\mathrm{g}}$ has been also observed in other polymer nanocomposite systems as for example PE with graphene [96].

\subsection{Dynamical Properties}

In this section we present data concerning the dynamical properties of polymer chains in the model nanocomposites with bare, and functionalized core/shell Au NPs. We perform the analysis by calculating corresponding quantities of PE chains, both as averages for the entire nanocomposite and as a function of distance from the PE/Au interface.

\subsubsection{Orientational Dynamics}

First, we study the orientational dynamics at the terminal level, via the reorientation time autocorrelation function ( $\mathrm{ACF}$ ) of the end-to-end vector, defined as: 


$$
C_{\text {end-end }}(t)=\frac{\langle R(t) \cdot R(0)\rangle}{\left\langle\|R\|^{2}\right\rangle}
$$

where $R(t)$ and $R(0)$ is the end-to-end vector at time $t$ and 0 respectively, $\|R\|$ is its magnitude, and \langle\rangle denotes statistical average. Results for the autocorrelation function, $C_{\text {end-end }}(t)$ at different radial adsorption layers are presented in Figure 7 for the hybrid PE100/Au5 system and the comparison with PE22/Au5 system in Appendix A Figure A6. In these figures corresponding data for a bulk PE system are also shown. It should be noted that we monitored the position of each vector only for the time period it belongs to the corresponding analysis regime in order to make these calculations. It is clear that in all systems slower PE chain dynamics at the vicinity of the Au nanoparticles is shown. In particular, PE chains in the first adsorption layers show much slower terminal dynamics compared to the bulk one. Then moving away from the Au NP surface up to a specific distance, we observed a more rapid decorrelation, whereas beyond this all curves coincide. We've also calculated the average value of the ACF for the entire system, which is almost identical with the bulk's one.

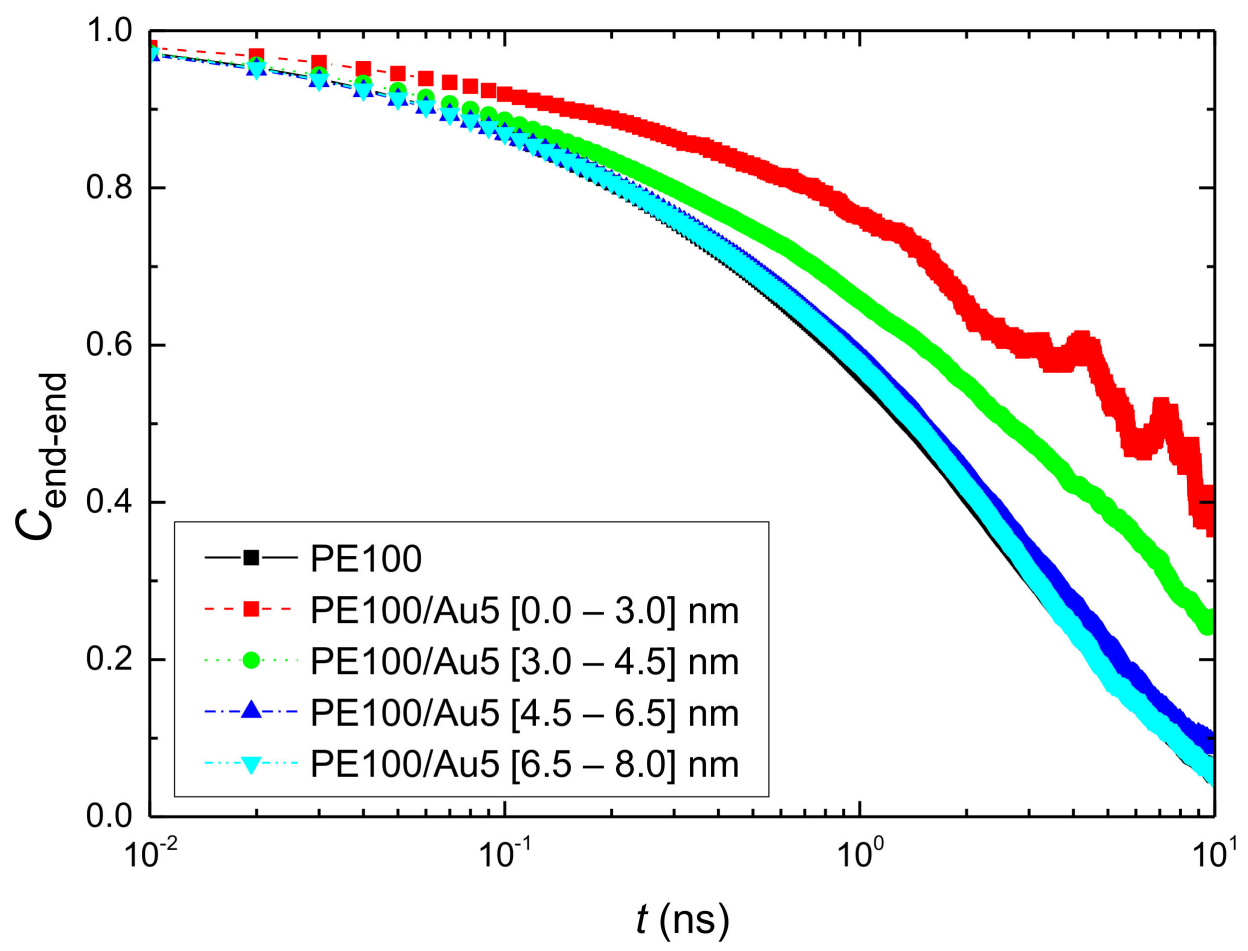

Figure 7. The reorientation time autocorrelation function (ACF) $C_{\text {end-end }}(t)$ as a function of time for the end-to-end vector of polyethylene for PE100/Au5 system. PE chains are analyzed across various shells from the Au NP.

The effect of the PE/gold nanoparticle interface on the PE terminal dynamics of each system can be further quantified by computing the corresponding chain relaxation times, through proper fits of curves shown in Figure 7, with a Kohlrausch-Williams-Watts (KWW) stretch exponential function [128] of the form:

$$
C_{\text {end-end }}(t)=\exp \left[-\left(\frac{t}{\tau_{\mathrm{KWW}}}\right)^{\beta}\right]
$$


where, $\tau_{\mathrm{KWW}}$ is the KWW relaxation time and $\beta$ the stretch exponent, which describes the broadness of the distribution of the relaxation times (i.e., the deviation from the ideal Debye behavior $\beta=1$ ). Then, the relaxation time, $\tau_{\text {end-end }}$, is calculated as the integral of the KWW curves through:

$$
\tau_{\text {end }- \text { end }}=\frac{\tau_{\mathrm{KWW}}}{\beta} \Gamma\left(\frac{1}{\beta}\right)
$$

where $\Gamma()$ is the gamma function.

The results of the above analysis for both the relaxation time $\tau_{\text {end-end }}$ and the $\beta$ exponent for PE chains of all the simulated systems are presented in Figures 8 and 9. Bulk values are also shown in these figures. It is clear that the PE chains which are very close to the $\mathrm{Au} \mathrm{NP}$, have much slower orientational dynamics (longer terminal relaxation time $\tau_{\text {end-end }}$ ) and $\tau_{\text {end-end }}$ is about 2-10 times longer than the bulk one. As expected polymer chains become more mobile as their distance from the gold nanoparticle increases, reaching a plateau, bulk-like regime, at distances of about 2.5-3.0 nm away from the Au NP. From the relaxation times reported in Figure 8 it is clear that the adsorbed polymer chains are (several times) slower than the ones in the bulk-like regime, however they are still mobile, as it is also shown below by probing the translational dynamics of polymer chains. In addition, $\beta$-exponent values of PE chains are smaller than the bulk value $(\sim 0.89)$, the black line shown in Figure 9, at the majority of all distances. The latter indicates a broader distribution of the polymer terminal dynamics, compared to the bulk one. Furthermore as was expected, the 100 mers PE systems have much slower relaxation times in comparison to those of the 22 mers PE systems (Appendix A Figures A7-A12).

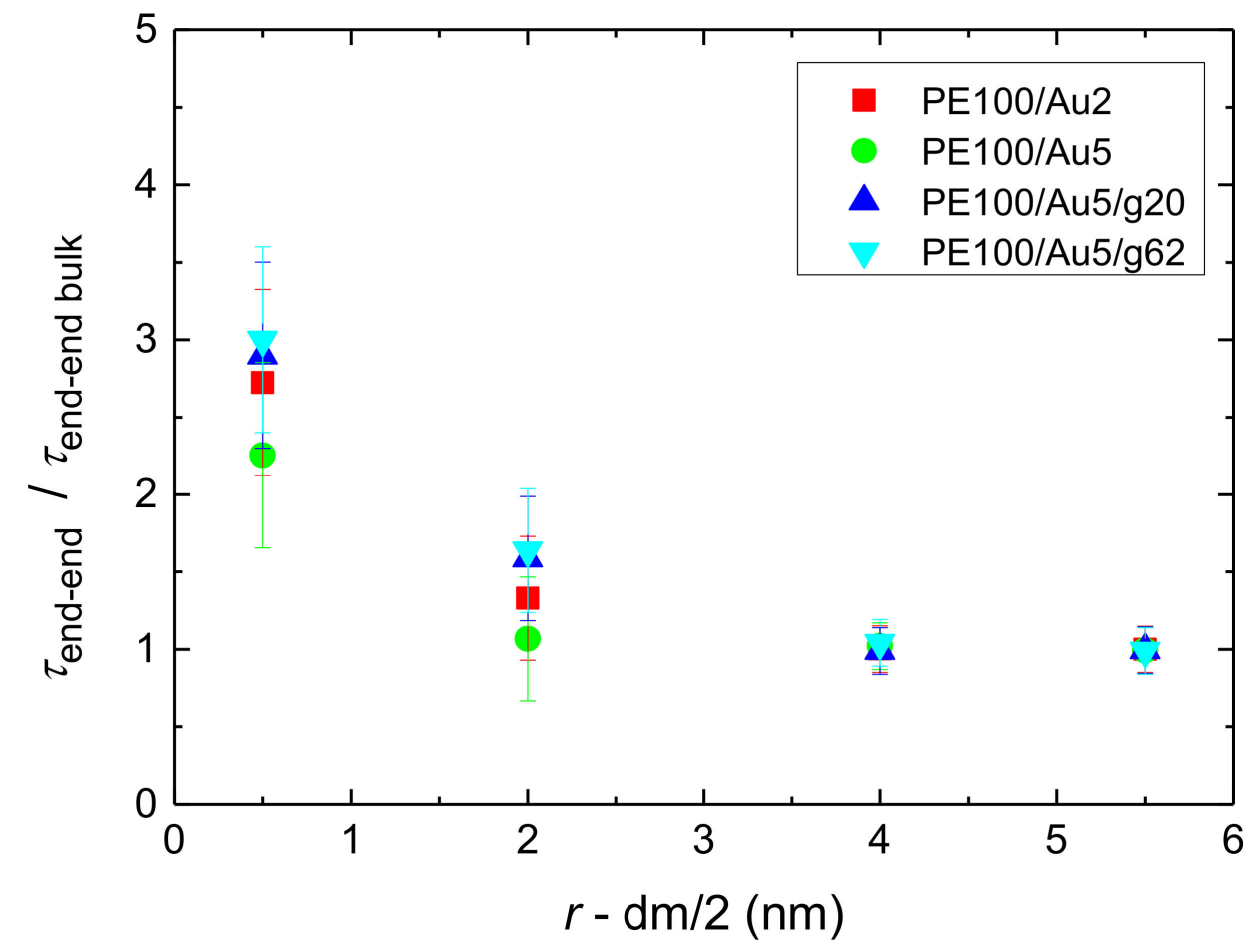

Figure 8. Relaxation time of the end-to-end vector of PE chains, scaled with the value of bulk chains,

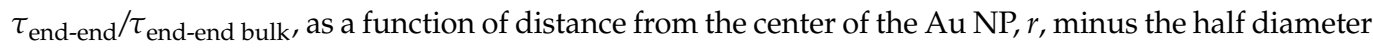
of the NP, for all systems with PE matrices consisting of 100 mers per chain. 


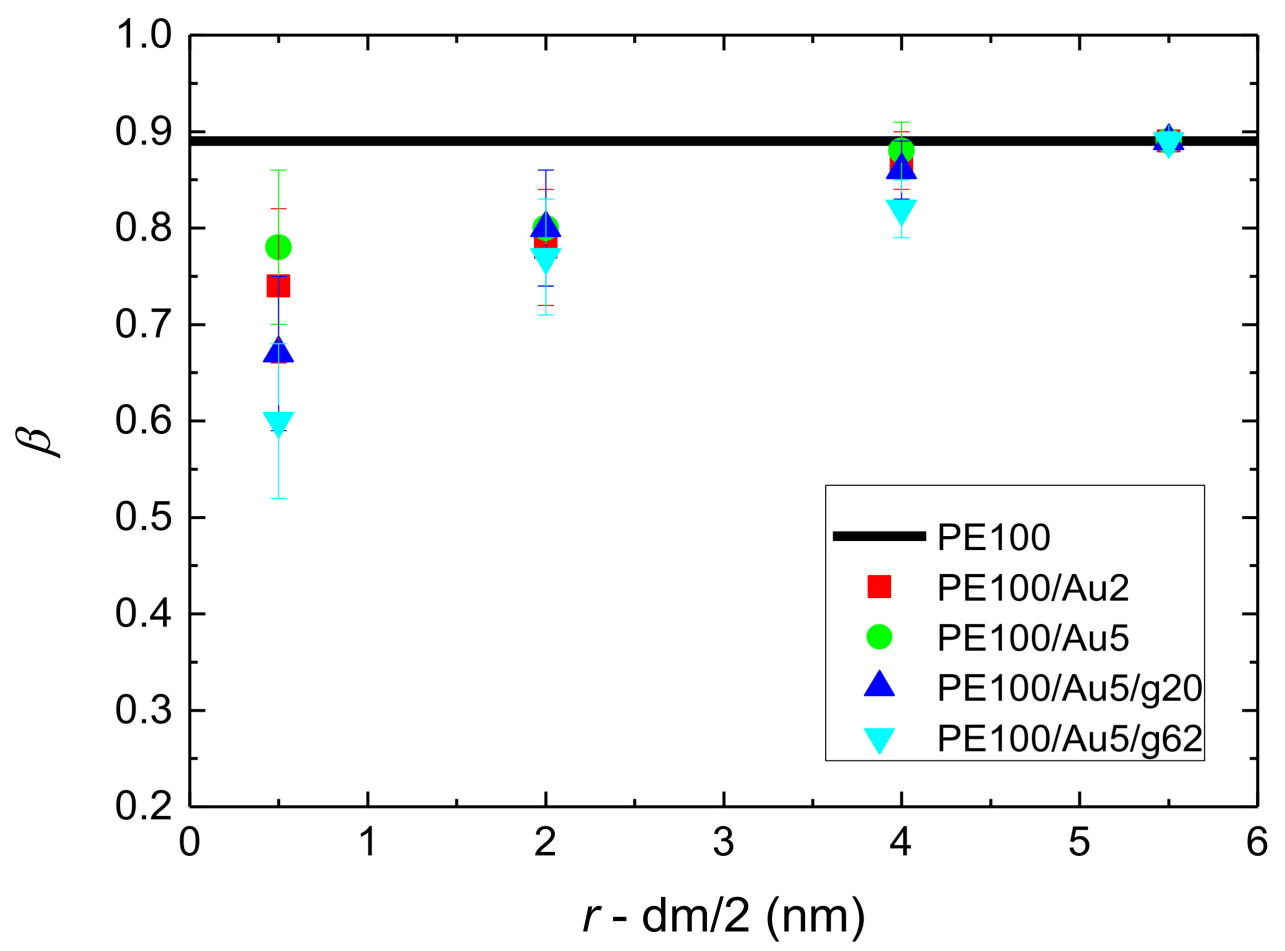

Figure 9. The stretch exponent $\beta$, as extracted from the fit with KWW functions, of the end-to-end vector ACF, $C_{\text {end-end }}(t)$, as a function of distance from the center of the Au NP, $r$, minus the half diameter of the NP for all systems with PE matrices consisting of 100 mers per chain. Black lines represent $\beta$ values of bulk PE chains.

\subsubsection{Translational Dynamics}

Next, the translational segmental dynamics of PE chains was examined. We have calculated the average segmental mean square displacement (MSD) in order to distinguish translational dynamics for different layers. The average segmental MSD is defined as:

$$
\Delta R_{j}(\tau)=\left\langle[r(t+\tau)-r(t)]^{2}\right\rangle
$$

where $j$ is a specific radial region, $r(t)$ and $r(t+\tau)$ are the coordinate vectors of a segment $\left(\mathrm{CH}_{2}\right.$ or $\mathrm{CH}_{3}$ group here) within region $j$, at time $t$ and $t+\tau$, respectively, and brackets \langle\rangle denote statistical average for all segments within the region $j$. Note, that in the analysis used here a segment contributes to the above MSD for a given time interval $\tau$ and for a radial region $j$, if and only if it was constantly present in that region in the entire course of time $\tau$. Data on $\Delta R_{j}(\tau)$ for all (radial) adsorption layers, scaled with $t^{0.5}$, for the PE100/Au5/g62 system is shown in Figure 10. We observed slower terminal dynamics of the polymer atoms closer to the Au NP atoms (mainly in the first adsorption layer) in comparison to the one of the atoms in the other layers. In contrast, chains which belong to the other regimes, (above the second layer) show quite similar dynamics, almost equal to the bulk one, the black line and the total average value of the entire system, the magenta line shown in Figure 10. All the simulated hybrid systems have a similar behavior. However, the PEs in PE22/Au2, PE22/Au5, PE22/Au5/g20 and PE22/Au5/g62 (see Appendix A Figure A13) are faster than the equivalent systems with PE matrices consisting of 100 mers per chain. 


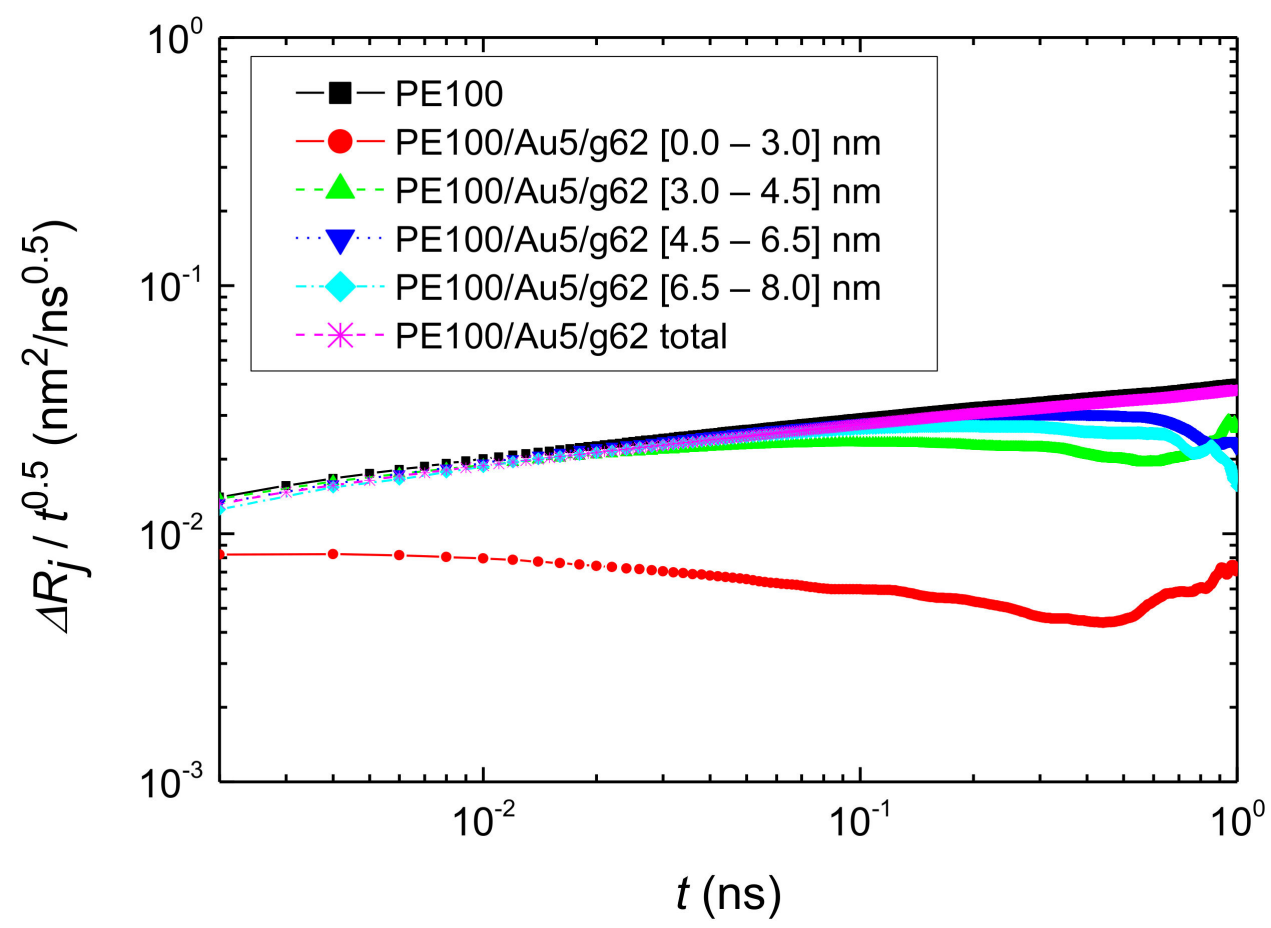

Figure 10. Segmental MSD of PE chains along $r$ (distance from the center of the gold NP), $\Delta R j$, scaled with $t^{0.5}$ Data for the PE100/Au5/g62 system, for various spherical shells, and the total MSD of the PE100 and PE100/Au5/g62 systems are shown.

According to the Rouse model predictions [69] $\Delta R_{j}(\tau) \propto \tau^{1 / 2}$. Our calculations using the data for bulk PE (PE100 system) showed that the Rouse regime was well-attained for the linear bulk chains, as it has been shown also in previous works [129-131]. Concerning the different adsorption spherical shells we extracted exponents less than $1 / 2$. Those exponents indicate the variation from the Rouse behavior which is more pronounced close to the Au NP. This attributed to the fact that there is attraction of the PE monomers from the Au NP and from the grafted polymers. Furthermore, according to our analysis method, we calculated the MSD for the hybrid systems as long as the segments were within the spherical shells. Therefore the time frame window is not enough to reach the Rouse regime for the PE monomers that are close to the surface of the Au NP.

The MSD at the 1st adsorption spherical shell, $\Delta R_{1}(\tau)$, scaled with $t^{0.5}$, is presented in Figure 11 for all simulated systems with PE matrices consisting of 100 mers per chain. We observe that the MSD, $\Delta R_{j}(\tau)$ in all systems for the 1st adsorption shell is smaller than the corresponding bulk one. Nevertheless, in qualitative agreement with the orientational segmental dynamics discussed above, chains in the first adsorption layer are still mobile. 


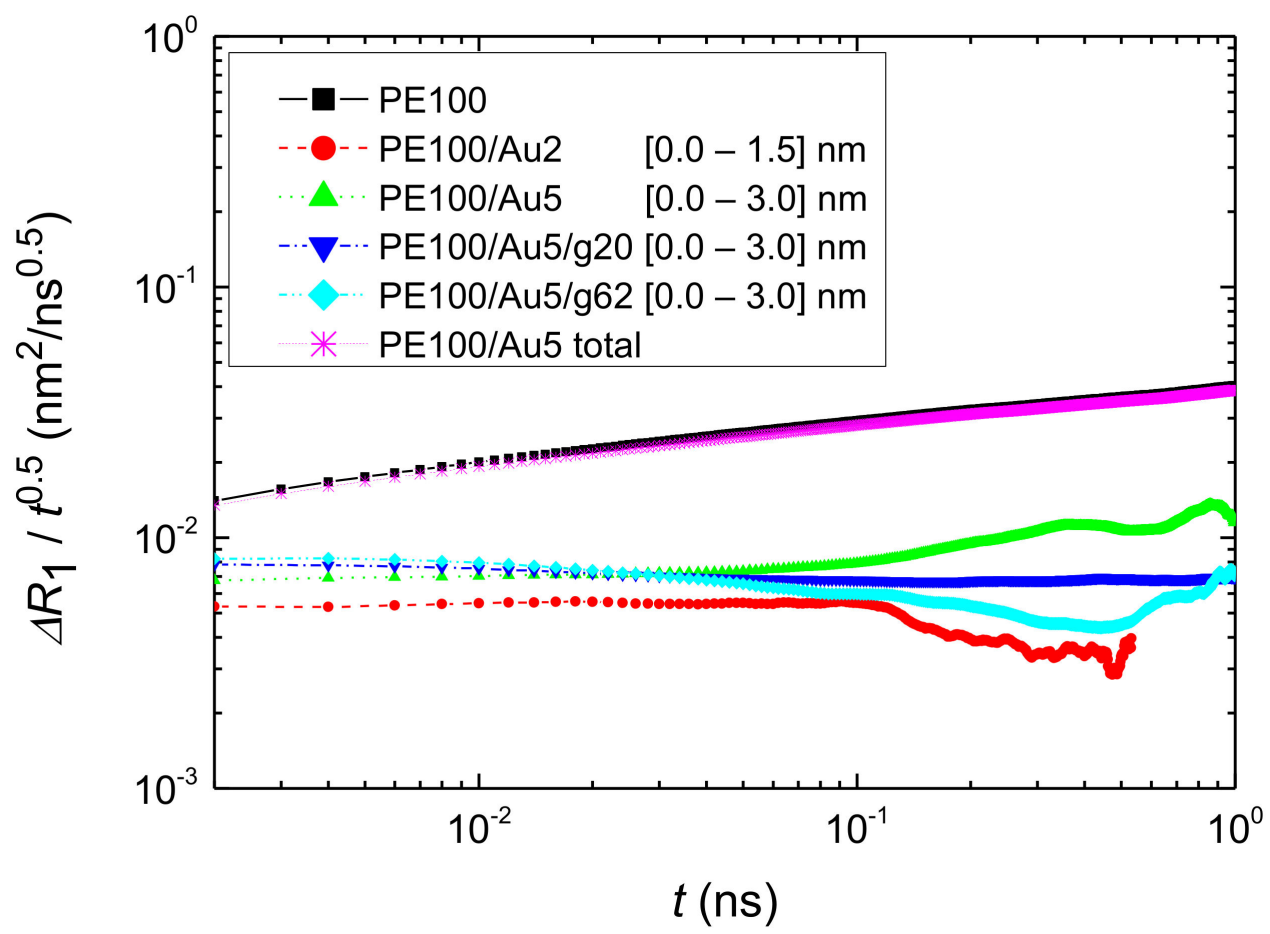

Figure 11. Segmental MSD of PE chains for the first adsorption spherical shell, $\Delta R_{1}$, scaled with $t^{0.5}$. Data for the PE100/Au2, PE100/Au5, PE100/Au5/g20 and PE100/Au5/g62 systems are shown, together with data about the MSD of the entire PE100 and PE100/Au5 systems.

\section{Discussion and Conclusions}

The term of interphase, a three-dimensional zone, is used to indicate a regime between two phases where properties are gradually changing from one phase to another, in contrast to the more traditional two-dimensional like "interface" one. For polymer nanocomposites the properties of polymer chains at the interphase are of paramount importance for the performance of these composite systems. Here, we studied, through detailed atomistic MD simulations, polymer nanocomposites with bare and core/shell metal (gold) NPs. Polyethylene chains of different molecular weights, consisting of 20 monomers per chain and 100 monomers per chain are used as a model polymer matrix. Au NPs were constructed in their equilibrium Wulff shape (minimum surface free energy) via DFT calculations. Two different $\mathrm{Au}$ NP sizes of $2.5 \mathrm{~nm}$ and $5.0 \mathrm{~nm}$ diameter were modeled. For the functionalized NPs grafted anchors of 20 and 62 monomers per anchor chain were considered. Various structural and dynamical properties of the PE chains were computed to examine the structure and the width of the PE/Au NP interphase.

The behavior of polyethylene is affected by the spatial heterogeneities induced by the presence of PE/Au NP interfaces. The average properties of the hybrid systems are, as expected, close to those of the bulk PE, due to the rather low concentration of the NPs. However, the dynamical properties of the polymers show big changes near the Au NPs as the relaxation times are 3 times higher than the bulk values. A detailed analysis was proposed based on averaging over atoms (or chains) within radial spherical shells equidistant from the center of the gold NP which allows us to examine the way that spatial heterogeneities are related to structural and dynamical features of the hybrid system as a function of distance from the polymer/gold nanoparticle interface.

From the analysis of the simulation it is clear that the width of the PE/Au NP interphase depends on the actual property under study. First, at the vicinity of the bare Au NPs a dense layer of polymer atoms appears. Second, for the case of the core/shell NPs the anchors change polymer's behavior/properties and especially the density profile. Furthermore, dynamics become slower close to the Au NP and terminal relaxation time decreases 
with the distance from the Au NP. Both NPs exhibit qualitatively the same influence on the segmental dynamics of PE chains. Nevertheless, there is a difference on the region defined from the center of the NP that is affected: It is about $2.5 \mathrm{~nm}$ for the small NP and about $4.0 \mathrm{~nm}$ for the larger one and as expected, the bigger the NP the larger the percentage of PE chains that are affected. Finally, the examined polymer properties attain their bulk-like values far from the Au NP's surface, whereas as expected by increasing the molecular weight, the density (slightly) increases and the dynamics become slower.

In Table 2 we summarize the effect of interface on various properties. Results can be summarized as follows:

- Local structural and conformational features were analyzed at the level of both individual segments (atoms or bonds) and entire chains. Due to the intermolecular PE/Au NP (adhesive) interaction the local monomer PE mass density exhibits a maximum near the gold surface. At short distances chain segments tend to orientate almost parallel to the Au NP surface. This randomizes gradually as the chain segments move away from the interface. Furthermore, in the dihedral angle distribution at the PE/gold NP interface we observed an increase of "trans" population compared to the bulk one. This reflects the more ordered polymer chain structures.

- Orientational relaxation of PE chains in the hybrid systems at the segmental and terminal level was quantified through the time autocorrelation function of a segmental vector and the end-to-end vector of PE chain respectively. In all cases the PE chains which were closer to the Au NP had much slower orientantional dynamics (segmental relaxation time, $\tau_{\text {seg, }}$ is about 10 times longer) in comparison to the bulk one. Moving away from the interface up to a specific distance, we noticed faster $C_{1-3}(t)$ decorrelation, while beyond this, all curves coincide. Moreover, we observed broader distribution of the polymer orientational dynamics in comparison to the bulk one (smaller $\beta$-exponent values).

- Translational segmental and center of masses dynamics of PE chains were examined by calculating the average mean-square displacement. Due to the polymer/gold nanoparticle interfaces, for all model hybrid systems, PE chains closer to the Au NP are slower, compared to the bulk one.

Table 2. The width of the interface in PE/au NP nanocomposites defined via different properties for the systems with 100 mers PE chains.

\begin{tabular}{ccc}
\hline Property & Bare Au NPs & Grafted Au NPs \\
\hline Density & $0.5-1.0 \mathrm{~nm}$ & $1.7-3.0 \mathrm{~nm}$ \\
Structural & $0.5-1.0 \mathrm{~nm}$ & $0.5-1.3 \mathrm{~nm}$ \\
Local (segmental) dynamics & $1.0-2.0 \mathrm{~nm}$ & $0.5-1.5 \mathrm{~nm}$ \\
Global dynamics & $3.0-4.0 \mathrm{~nm}$ & $1.0-2.0 \mathrm{~nm}$ \\
\hline
\end{tabular}

The above findings, beside their obvious relevance to scientific questions regarding the influence of metal (Au) NPs on the properties of the polymer matrix might have also implications to technological applications, as the properties of the polymer/metal interface affect the functional properties of the hybrid material. As an example, polymer mass density profiles are directly related to the actual polymer/NP interaction.

From the technological point of view, an interesting aspect concerns the comparison of the different model systems studied in this work, as candidates for given technological applications. This is a non-trivial issue, since which model system is the "best one" depends strongly on the specific application. In general, for cases where strong interaction between polymer and metal NPs is necessary PE/ Au nanocomposites (NCs) with bare NPs are advantageous. On the contrary, for cases were better dispersion of the Au NPs and more theta-solvent like polymer-Au interactions are desired, PE/Au NCs with core-shell Au NPS are a better choice. 
Polymer nanocomposites have been studied via molecular simulations. However, limited are the works concerning PNCs with metal NPs. The results presented here are a first step towards a fundamental understanding of specific polymer/metal (here PE/Au) nanocomposites via detailed atomistic simulations. To achieve this, additional works providing systematic investigations of the role of chemistry and of specific interactions on the properties of polymer/metal nanocomposites are required. Examples include PNCs with metal NPs of different size and shape, of different polymer matrix (e.g., conductive polymers), or systems with core-shell NPs of different grafting density.

Another interesting issue concerns the dispersion of the metal $(\mathrm{Au}) \mathrm{NPs}$ in the polymer matrix, which depends strongly on the actual polymer/NP and NP/NP interactions. In this work a single NP has been used, so it is not possible to directly study the dispersion of $\mathrm{Au}$ NPs. However the polymer mass density profiles at the interface is a direct evidence of the polymer/NP interaction. From these data we can speculate that the interaction of PE chains with the core-shell Au NPs is more like a theta solvent, since the hair have the same chemistry as the matrix. Therefore, we would expect that these NPs could disperse better in the polymer matrix than the bare ones [132]. Moreover, we can assume that the longer the grafted chains and the higher the grafting density the better the dispersion of the core-shell $\mathrm{Au}$ NPs in the PE matrix. This could be further studied by calculating the potential of mean force between two NPs. All of them are potential directions for future work.

Supplementary Materials: The following is available online at https:/ / www.mdpi.com/2073-4360/ 13/4/541/s1, Video S1: PE-grafted AuNP. Video from MD simulation of hybrid polyethylene/grafted gold nanoparticle at $450 \mathrm{~K}$. Au nanoparticle (2461 atoms, diameter of $5.04 \mathrm{~nm}$ ) and polyethylene (1200 chains, 100-mers per chain) are shown. In yellow is the Au and in grey are the edges of $\mathrm{Au}$ nanoparticle. In blue are the free $\mathrm{CH}_{2}$ and the free $\mathrm{CH}_{3}$ monomers. In red are the grafted $\mathrm{CH}_{2}$ and $\mathrm{CH}_{3}$ monomers.

Author Contributions: Investigation, A.J.P. and I.N.R.; Supervision, V.H.; writing—original draft, A.J.P.; writing-review and editing, V.H. All authors have contributed in all parts of the present work. All authors have read and agreed to the published version of the manuscript.

Funding: The research work was supported by the Hellenic Foundation for Research and Innovation (HFRI) and the General Secretariat for Research and Technology (GSRT), under the HFRI PhD Fellowship grant (GA. no. 2406) and Project MULTIGOLD numbered 1303-KA10480, by the European Union and Greek national funds through the Operational Program Competitiveness, Entrepreneurship and Innovation, under the call RESEARCH-CREATE-INNOVATE (project code:T1EDK-02746, MIS 5031809) and by the University of Crete, Grants for PhD Candidates. This research is partially supported by the project "National Research Infrastructure on nanotechnology, advanced materials and micro/nanoelectronics" (MIS 5002772) implemented under the "Action for the Strategic Development on the Research and Technological Sector", funded by the Operational Programme "Competitiveness, Entrepreneurship and Innovation" (NSRF 2014-2020) and co-financed by Greece and the European Union (European Regional Development Fund). V.H. acknowledges support by project SimEA, funded by the European Union's Horizon 2020 research and innovation programme under grant agreement No 810660.

Data Availability Statement: The data presented in this study are available on request from the corresponding author.

Acknowledgments: The work was supported by computational time granted from the Greek Research \& Technology Network (GRNET) in the National HPC facility--ARIS under projects named MODYN-SHYPONAS and CDPrSc. We thank Anastassia Rissanou, Petra Bačová and Alireza Behbahani for constructive discussions about the project. Albert John Power thanks Melita Power and Eleftheria Ieronymaki for their insightful comments.

Conflicts of Interest: The authors declare no conflict of interest. The funders had no role in the design of the study; in the collection, analyses, or interpretation of data; in the writing of the manuscript, or in the decision to publish the results. 


\section{Appendix A}
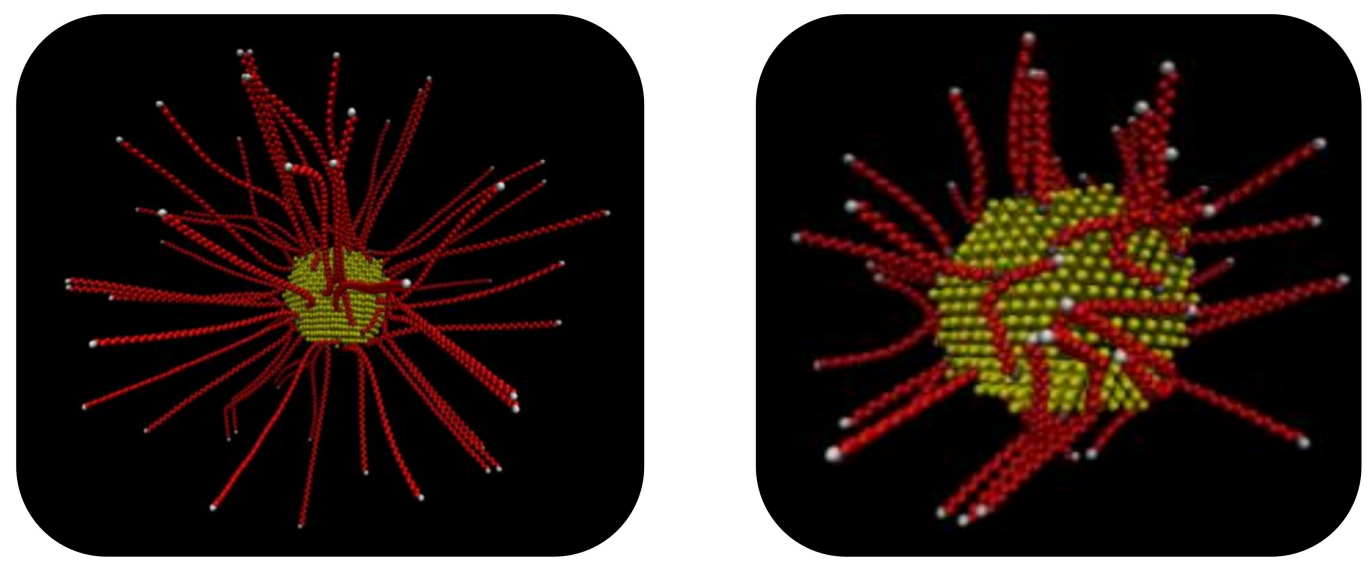

Figure A1. Snapshot from MD simulation of hybrid polyethylene/grafted gold nanoparticle at $450 \mathrm{~K}$. Au nanoparticle (2461 atoms, diameter of $5.04 \mathrm{~nm}$ ) is shown. In yellow is the $\mathrm{Au}$ and in grey are the terminal $\mathrm{CH}_{3}$ groups. In red are the grafted $\mathrm{CH}_{2}$ and the grafted $\mathrm{CH}_{3}$ monomers. The initial configuration of the grafted NP with the short anchored polymeric chains and with the long anchored polymeric chains.

Table A1. Non-bonded interactions of the atomistic force field for the model PE/Au nanocomposites.

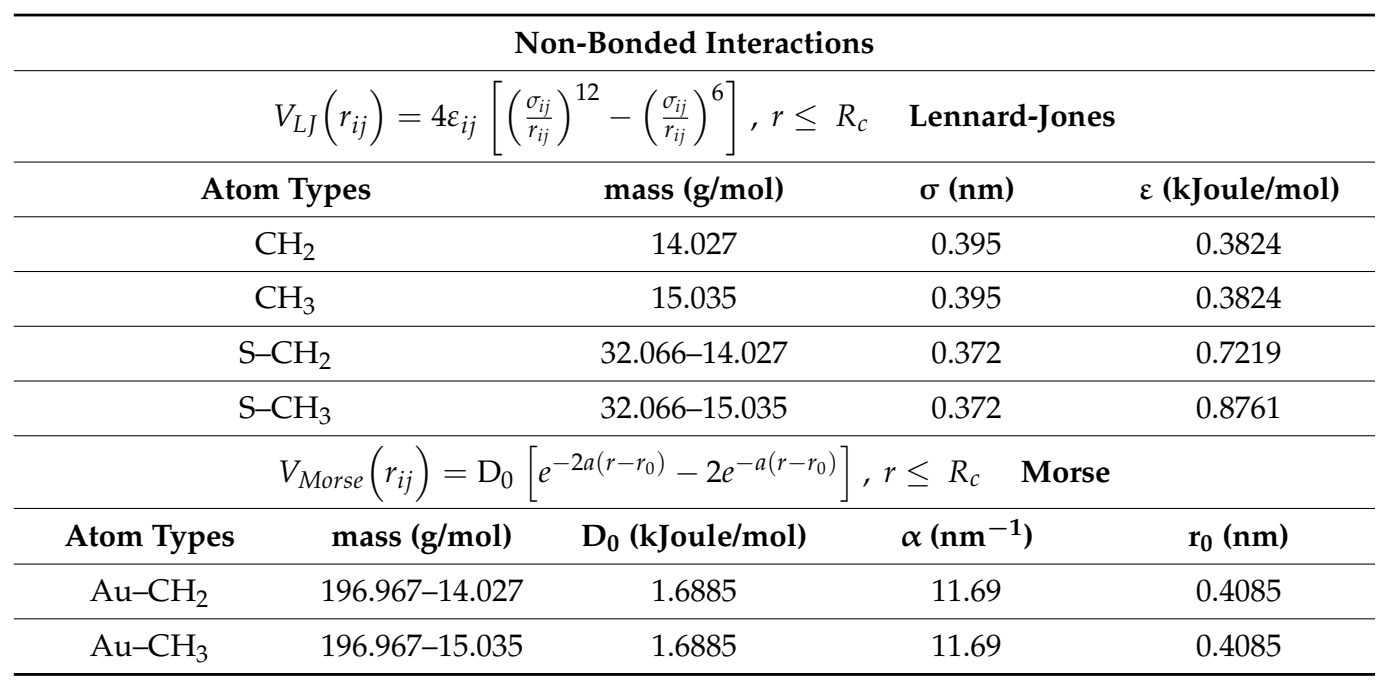

Table A2. Bonded interactions of the atomistic force field for the model PE/Au nanocomposites.

\begin{tabular}{ccc}
\hline & Bonded Interactions & \\
\hline Bond & $V_{b}\left(r_{i j}\right)=\frac{1}{2} k_{i j}^{b}\left(r_{i j}-b_{i j}\right)^{2}$ & $\mathbf{k}^{\mathbf{b}}\left(\mathbf{k J} / \mathbf{m o l}^{-\mathbf{n m}} \mathbf{2}^{\mathbf{2}}\right.$ \\
\hline $\mathrm{CH}_{2}-\mathrm{CH}_{2}$ & $\mathbf{b} \mathbf{( n m )}$ & $100,000.00$ \\
\hline $\mathrm{CH}_{2}-\mathrm{CH}_{3}$ & 0.154 & $100,000.00$ \\
\hline $\mathrm{CH}_{3}-\mathrm{CH}_{2}$ & 0.154 & $100,000.00$ \\
\hline $\mathrm{S}-\mathrm{CH}_{2}$ & 0.154 & fixed \\
\hline
\end{tabular}


Table A2. Cont.

\begin{tabular}{|c|c|c|c|c|}
\hline \multicolumn{5}{|c|}{ Bonded Interactions } \\
\hline \multicolumn{5}{|c|}{$V_{\alpha}\left(\theta_{i j k}\right)=\frac{1}{2} k_{i j k}^{\Theta}\left(\theta_{i j k}-\theta_{i j k}^{0}\right)^{2}$} \\
\hline Angle & & $\theta^{\circ}$ (deg) & \multicolumn{2}{|c|}{$\mathbf{k}^{\theta}\left(\mathrm{kJ} / \mathrm{mol}^{*} \mathrm{rad}^{2}\right)$} \\
\hline $\mathrm{CH}_{2}-\mathrm{CH}_{2}-\mathrm{CH}_{2}$ & & 114 & \multicolumn{2}{|c|}{519.611} \\
\hline $\mathrm{CH}_{3}-\mathrm{CH}_{2}-\mathrm{CH}_{2}$ & & 114 & \multicolumn{2}{|c|}{519.611} \\
\hline $\mathrm{CH}_{2}-\mathrm{CH}_{2}-\mathrm{CH}_{3}$ & & 114 & \multicolumn{2}{|c|}{519.611} \\
\hline $\mathrm{S}-\mathrm{CH}_{2}-\mathrm{CH}_{2}$ & & 114 & \multicolumn{2}{|c|}{519.611} \\
\hline \multicolumn{5}{|c|}{$V_{o p l s}\left(\varphi_{i j k l}\right)=\frac{1}{2} K_{1}[1+\cos (\varphi)]+\frac{1}{2} K_{2}[1-\cos (2 \varphi)]+\frac{1}{2} K_{3}[1+\cos (3 \varphi)]+\frac{1}{2} K_{4}[1-\cos (4 \varphi)]$} \\
\hline Dihedral & $K_{1}(\mathrm{KJ} / \mathrm{mol})$ & $K_{2}(\mathrm{KJ} / \mathrm{mol})$ & $K_{3}(\mathrm{KJ} / \mathrm{mol})$ & $K_{4}(\mathrm{KJ} / \mathrm{mol})$ \\
\hline $\mathrm{CH}_{3}-\mathrm{CH}_{2}-\mathrm{CH}_{2}-\mathrm{CH}_{2}$ & 4.276 & -1.12968 & 13.1545 & 0.00 \\
\hline $\mathrm{CH}_{2}-\mathrm{CH}_{2}-\mathrm{CH}_{2}-\mathrm{CH}_{2}$ & 4.276 & -1.12968 & 13.1545 & 0.00 \\
\hline $\mathrm{CH}_{2}-\mathrm{CH}_{2}-\mathrm{CH}_{2}-\mathrm{CH}_{3}$ & 4.276 & -1.12968 & 13.1545 & 0.00 \\
\hline $\mathrm{S}-\mathrm{CH}_{2}-\mathrm{CH}_{2}-\mathrm{CH}_{2}$ & 4.276 & -1.12968 & 13.1545 & 0.00 \\
\hline
\end{tabular}

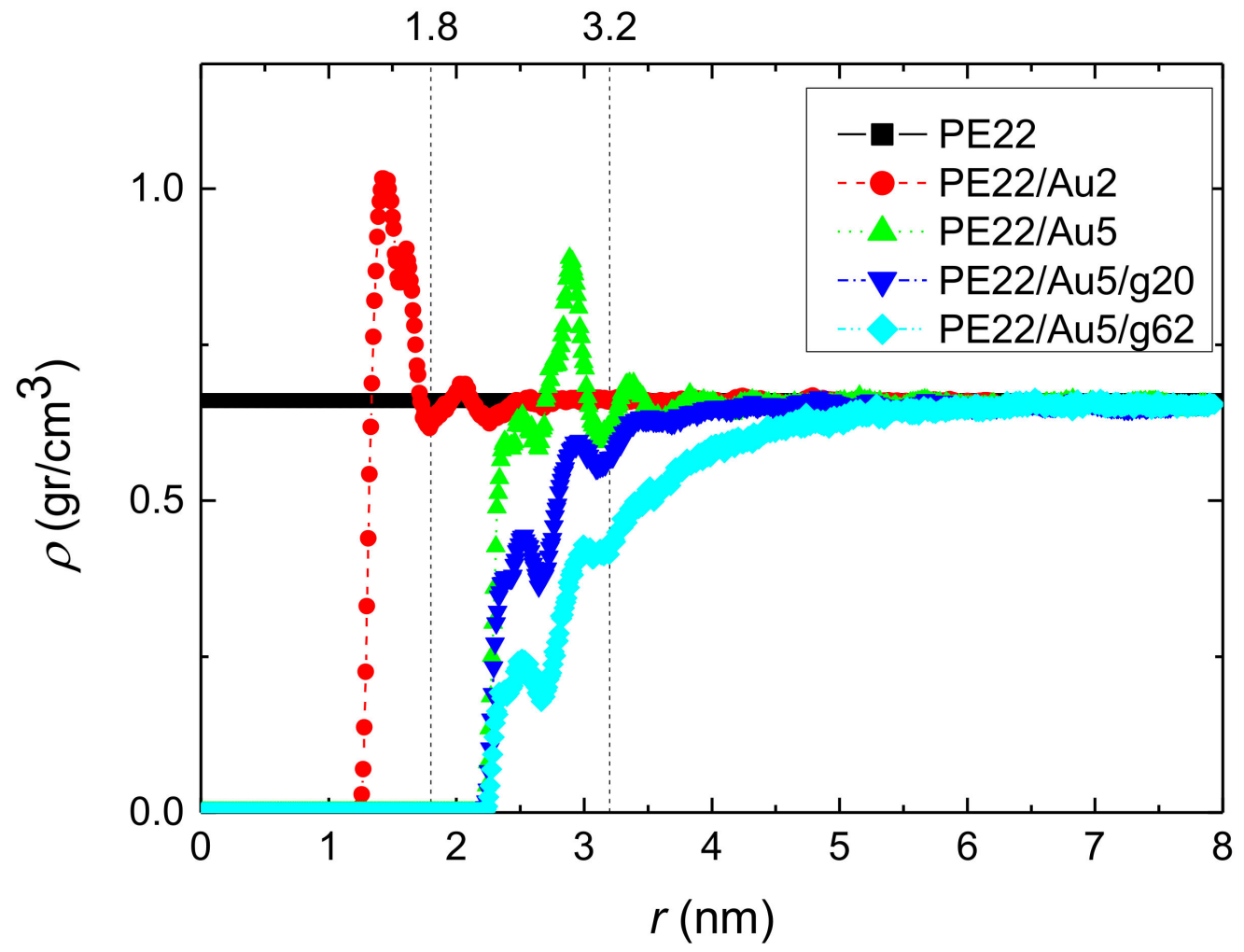

Figure A2. Mass monomer density profiles of PE chains as a function of distance from the center of the gold NP, $r$, for the systems: PE22, PE22/Au2, PE22/Au5, PE22/Au5/g20 and PE22/Au5/g62. 


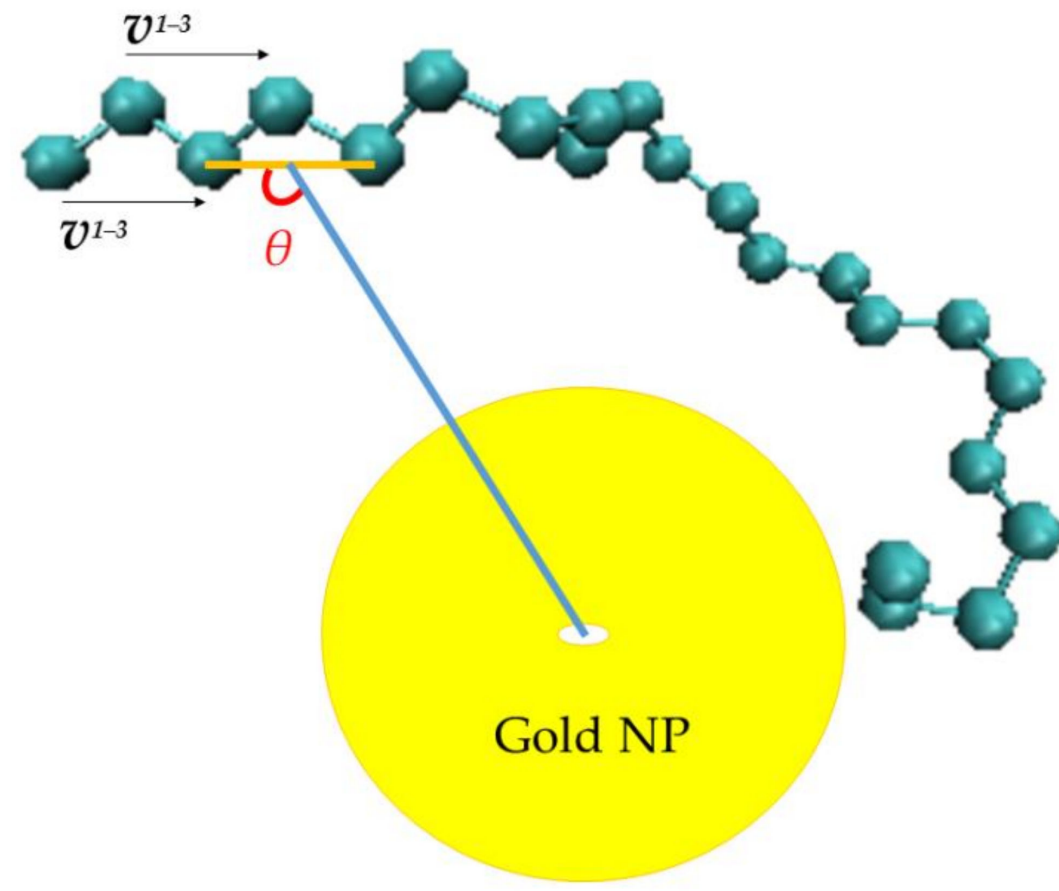

Figure A3. The definition of the $\theta$ angle for the calculation of the second rank bond order parameter $S_{1-3}$ of polyethylene chains for $v^{1-3}$ vector. In blue is the PE and in yellow is the Au NP. The orange line connects two non-consecutive carbon atoms and the blue line connects the center of the gold NP with the midpoint of the orange line. In red is the $\theta$ angle.

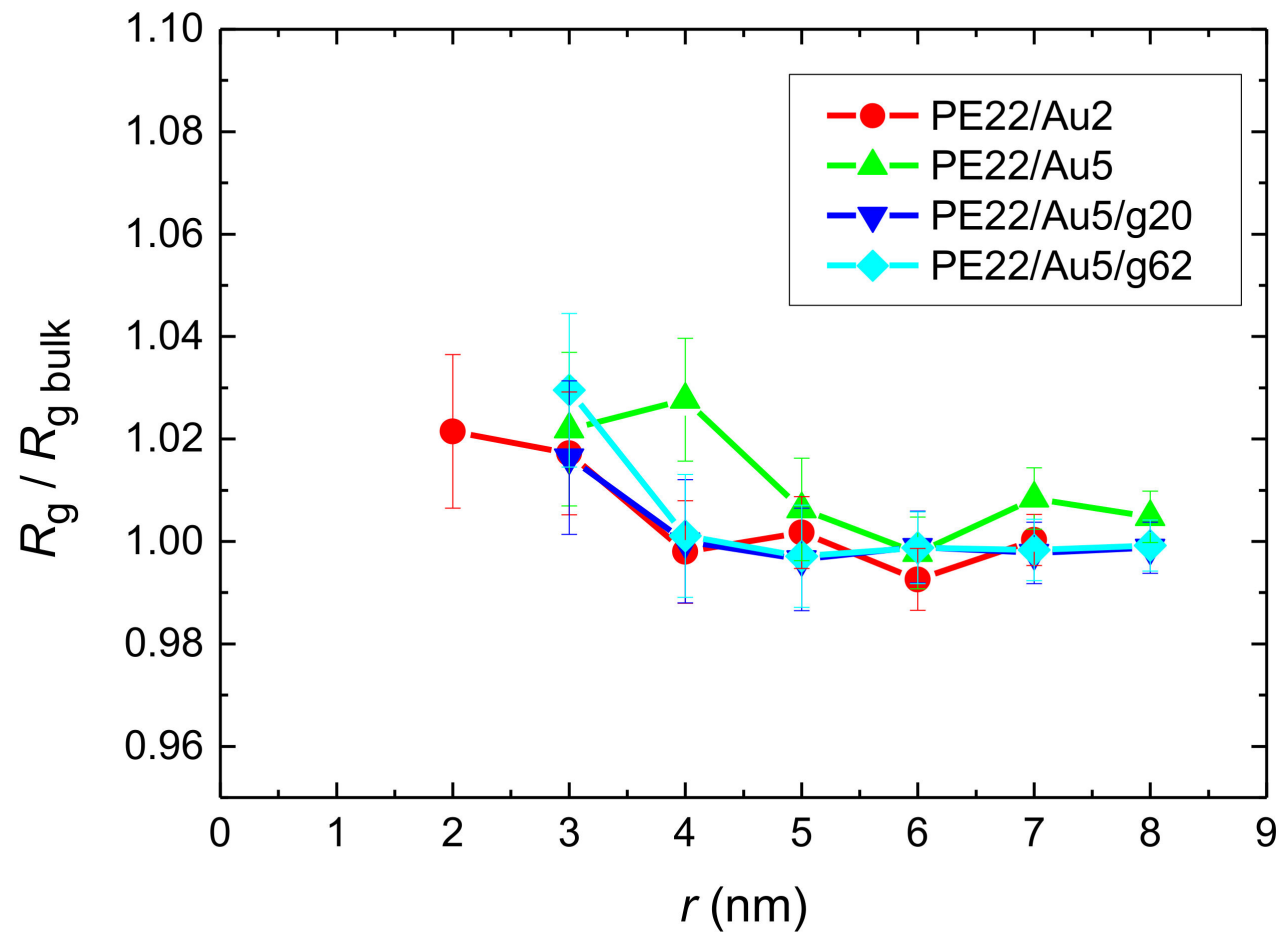

Figure A4. Radius of gyration of PE chains, scaled with its bulk value $\left(R_{\mathrm{g} /} R_{\mathrm{g} \text { bulk }}\right)$ as a function of $r$ distance from the center of the Au NP. Data for the PE22, PE22/Au2, PE22/Au5, PE22/Au5/g20 and $\mathrm{PE} 22 / \mathrm{Au} 5 / \mathrm{g} 62$ systems are shown. 


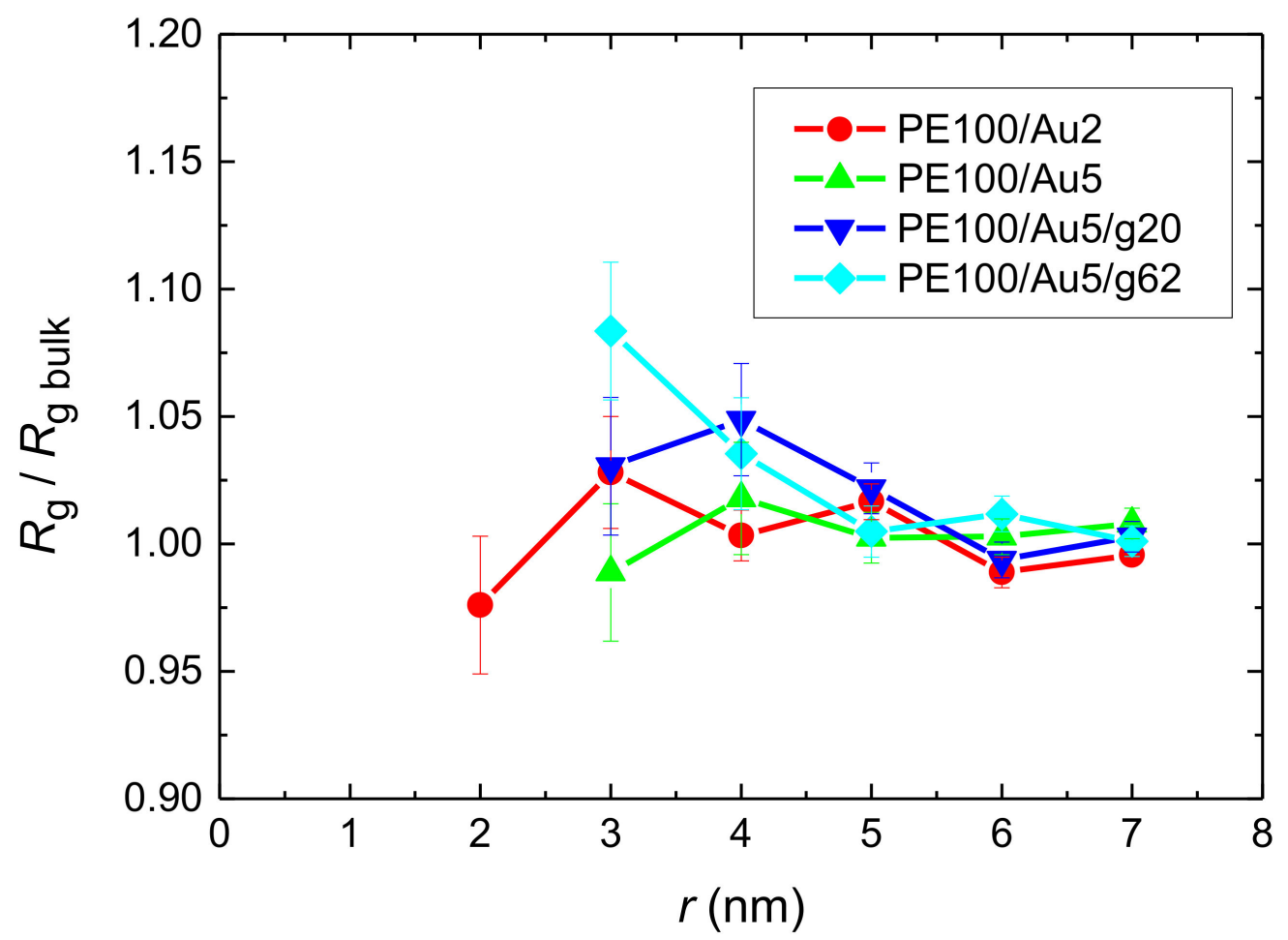

Figure A5. Radius of gyration of PE chains, scaled with its bulk value $\left(R_{\mathrm{g} /} R_{\mathrm{g}}\right.$ bulk $)$ as a function of distance, $r$, from the center of the gold NP. Data for the PE100, PE100/Au2, PE100/Au5, PE100/Au5/g20 and PE100/Au5/g62 systems are shown.

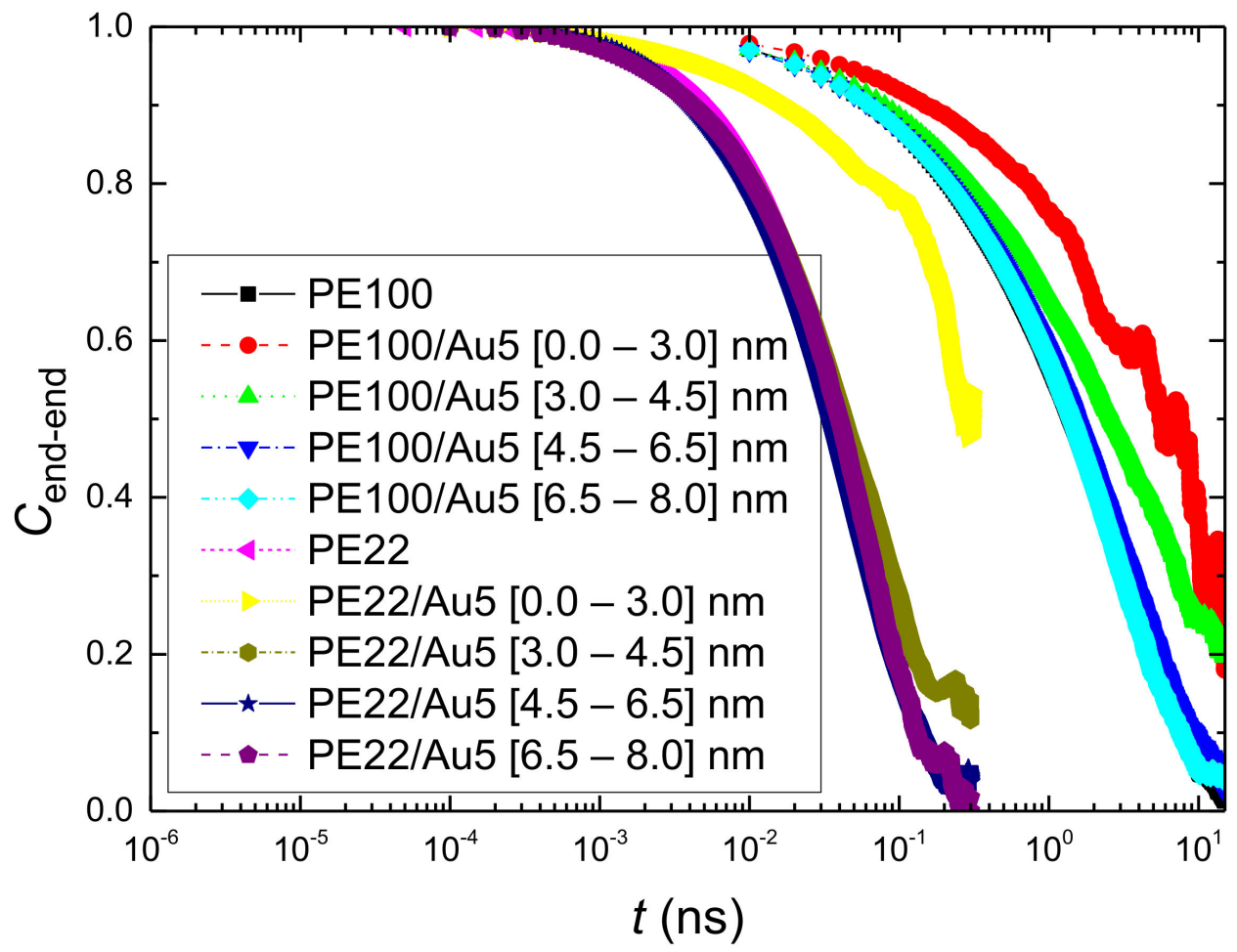

Figure A6. Time ACF of the end-to-end vector of PE chains, $C_{\text {end-end }}(t)$, as a function of time for PE22/Au5 and PE100/Au5 systems. $C_{\text {end-end }}(t)$ values for the PE22/Au5 and PE100/Au5 systems, for various spherical shells are presented. 
Below in Figures A6-A9 data about the segmental dynamics of the PE chains are shown. We follow a methodology similar to the one for the end-to-end vector. First, we compute the angle $\theta$ of a segmental $1-3$ vector, $v^{1-3}$, at time $t$ relative to its position at $t=0$. Second, we calculate the second order Legendre polynomial (correlation function) for this vector, defined as:

$$
C_{1-3}(t)=\frac{3}{2}\left(\langle\cos \theta(t) \cos \theta(0)\rangle-\frac{1}{2}\right)
$$

Then, we fit $C_{1-3}(t)$ using a KWW function and derive the characteristic segmental relaxation time, $\tau_{\text {seg }}$ and the corresponding $\beta$-exponent, by computing the integral below the KWW curve, similar to the analysis followed for the end-to-end vector ACFs.

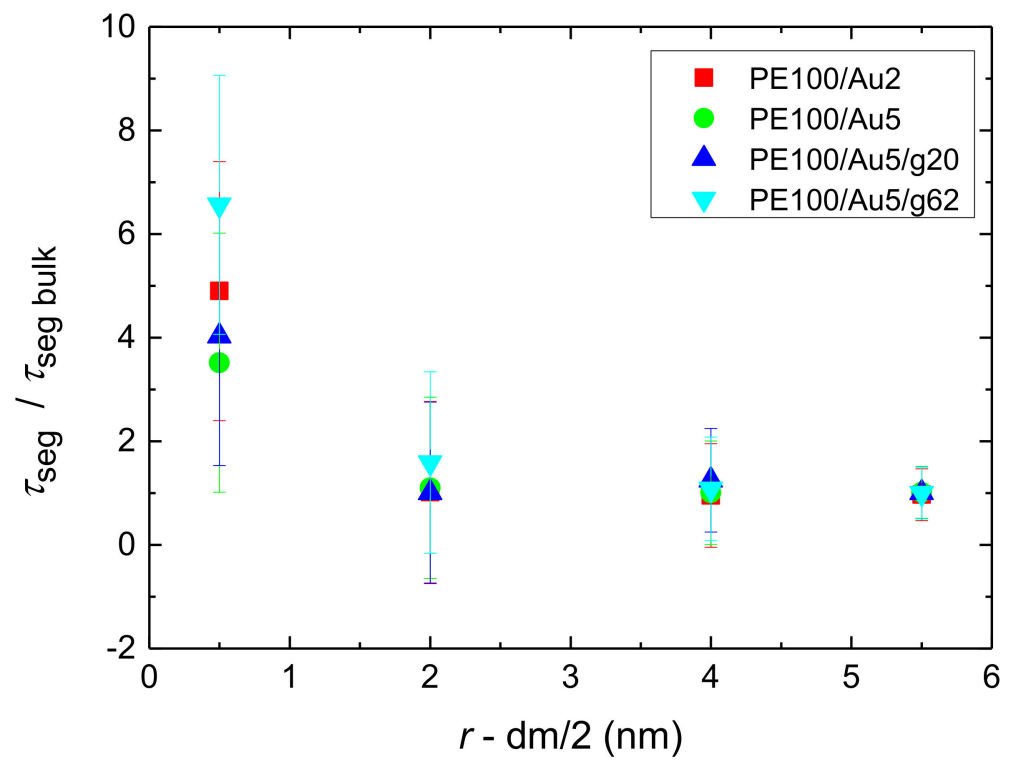

Figure A7. Segmental relaxation times of PE chains, scaled with the value of bulk chains, $\tau_{\text {seg }} / \tau_{\text {seg bulk }}$, as a function of distance from the center of the $\mathrm{Au} \mathrm{NP}, r$, minus the half diameter of the NP, for all systems with PE matrices consisting of 100 mers per chain.

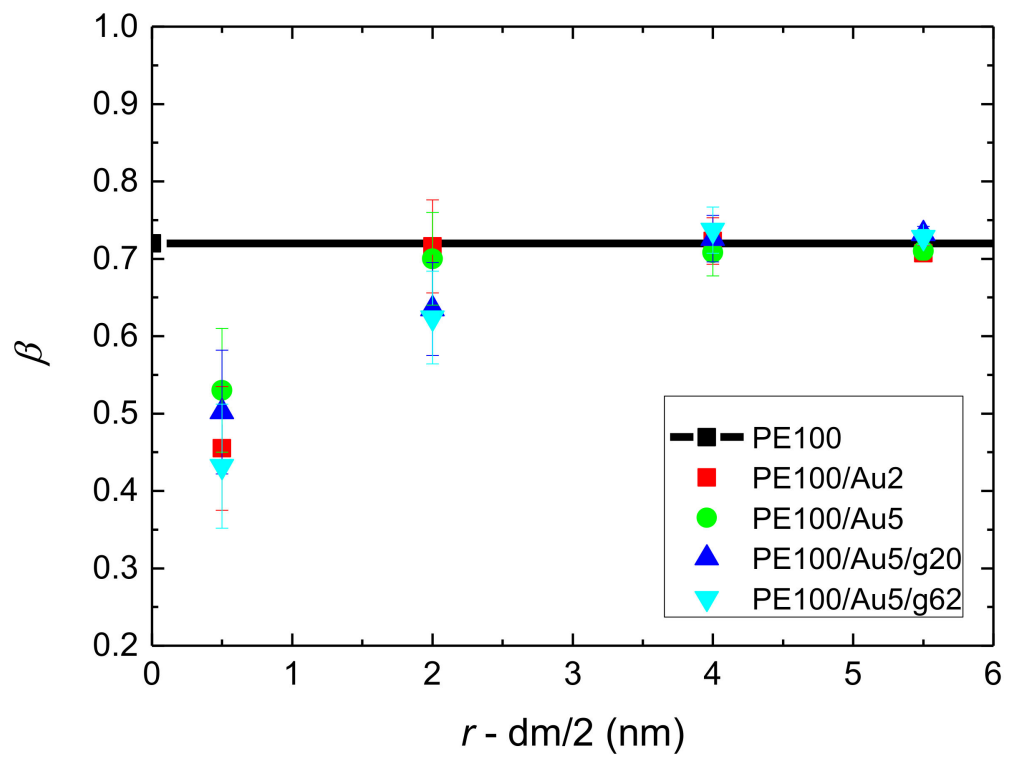

Figure A8. The stretch exponent $\beta$, as extracted from the fit of $C_{1-3}(t) \mathrm{ACF}$ with a KWW, as a function of distance from the center of the Au NP, $r$, minus the half diameter of the NP, for all systems with PE matrices consisting of 100 mers per chain. Black lines represent $\beta$ values of bulk PE. 


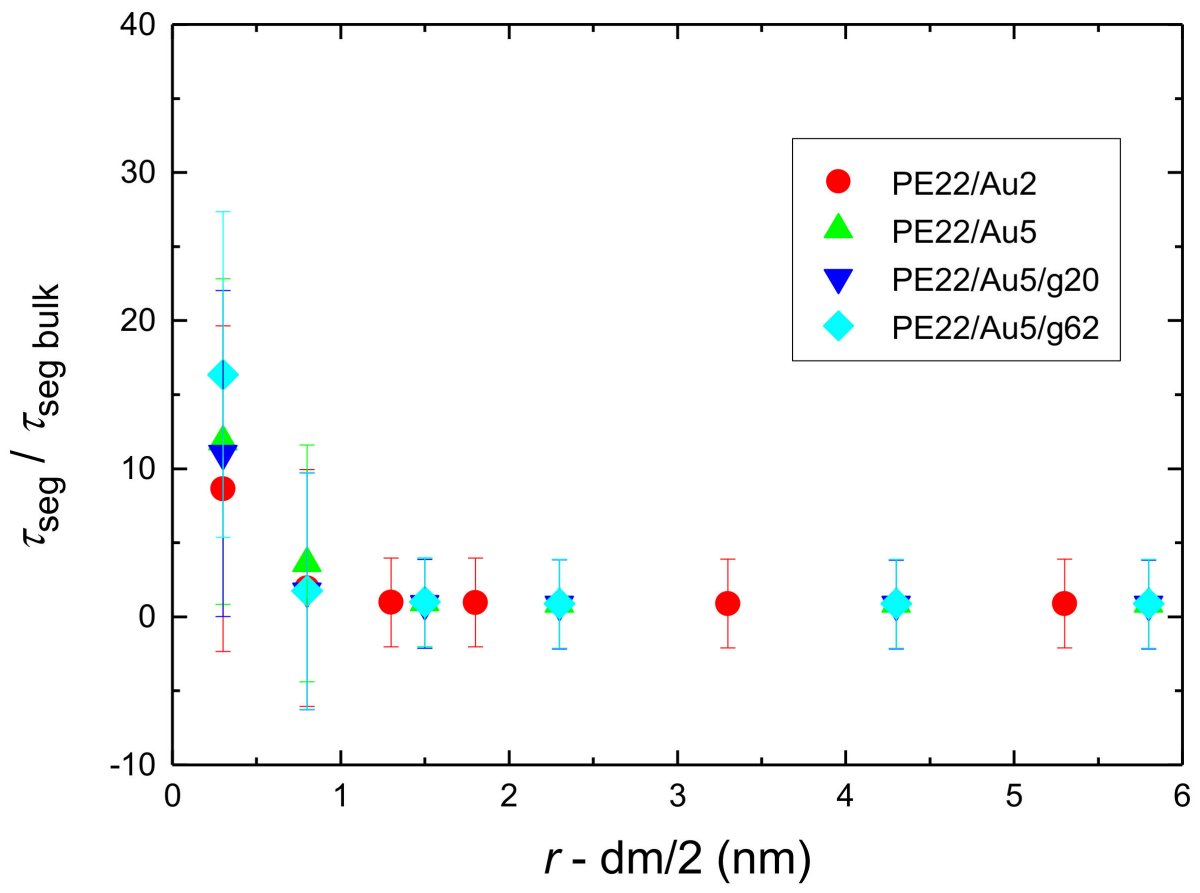

Figure A9. Segmental relaxation times of PE chains, scaled with the value of bulk chains, $\tau_{\text {seg }} / \tau_{\text {seg bulk }}$, as a function of distance from the center of the $\mathrm{Au} \mathrm{NP}, r$, minus the half diameter of the NP, for all systems with PE matrices consisting of 22 mers per chain.

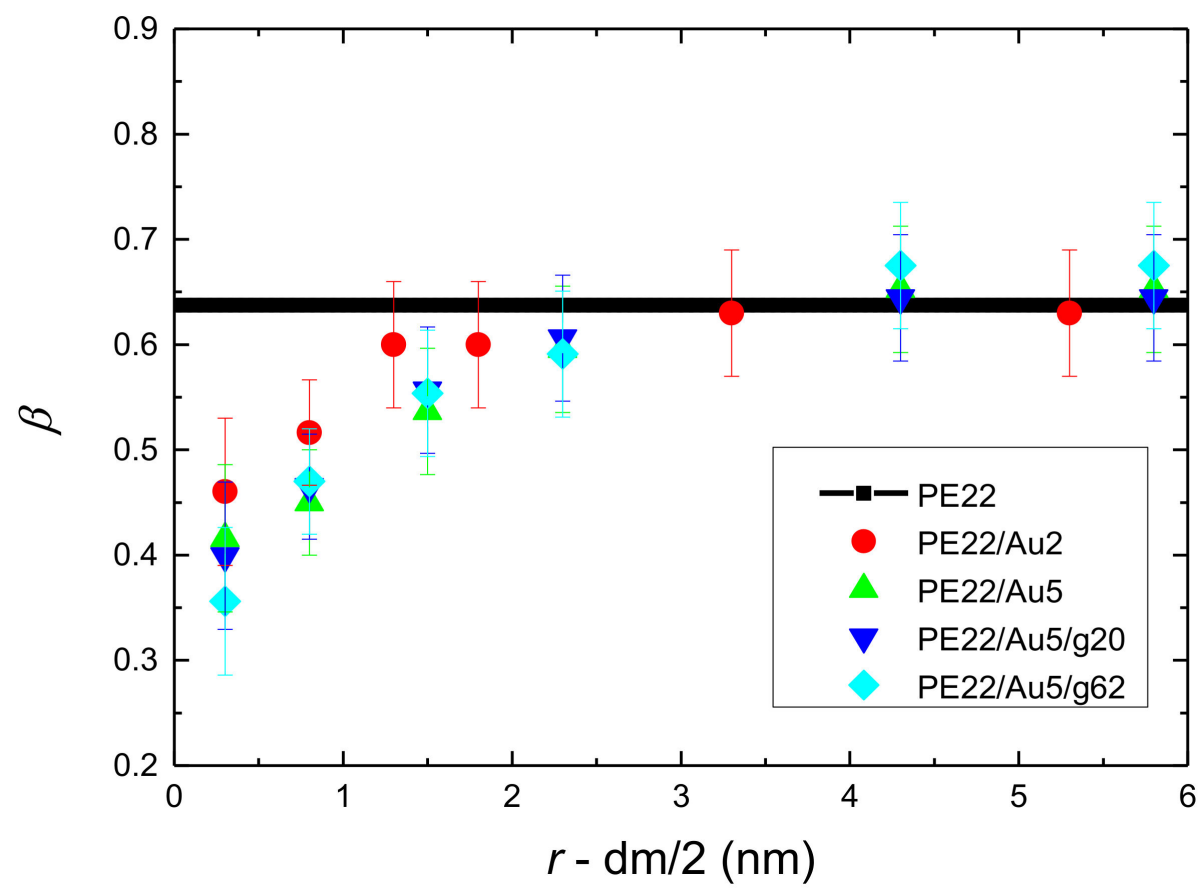

Figure A10. The stretch exponent $\beta$, as extracted from the fit of $C_{1-3}(t)$ ACF with a KWW, as a function of distance from the center of the Au NP, $r$, minus the half diameter of the NP, for all systems with PE matrices consisting of 22 mers per chain. Black lines represent $\beta$ values of bulk PE. 


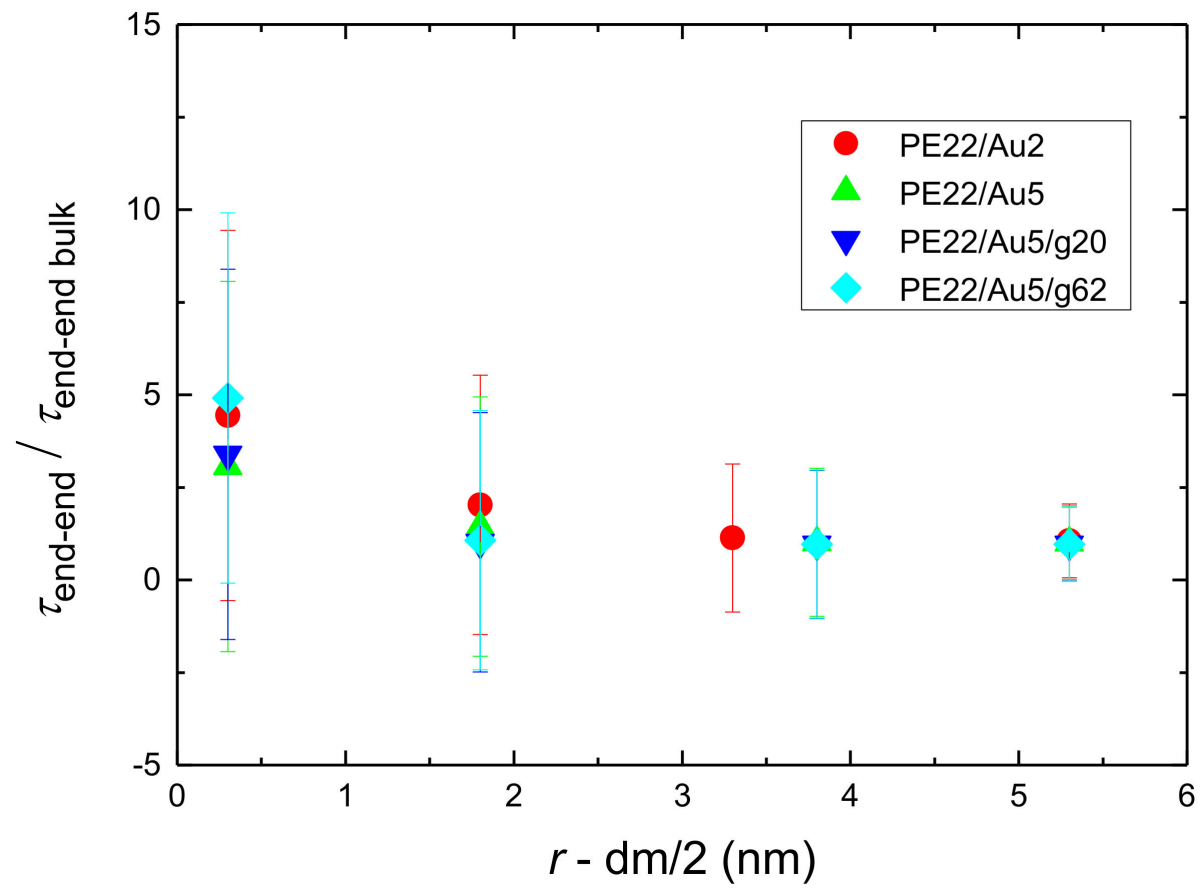

Figure A11. Terminal relaxation times of PE chains derived for the end-to-end vector ACF, $C_{\text {end-end }}(t)$, scaled with the value of bulk chains, $\tau_{\text {end-end }} / \tau_{\text {end-end bulk, }}$ as a function of distance from the center of the Au NP, $r$, minus the half diameter of the NP for all systems with PE matrices consisting of 22 mers per chain.

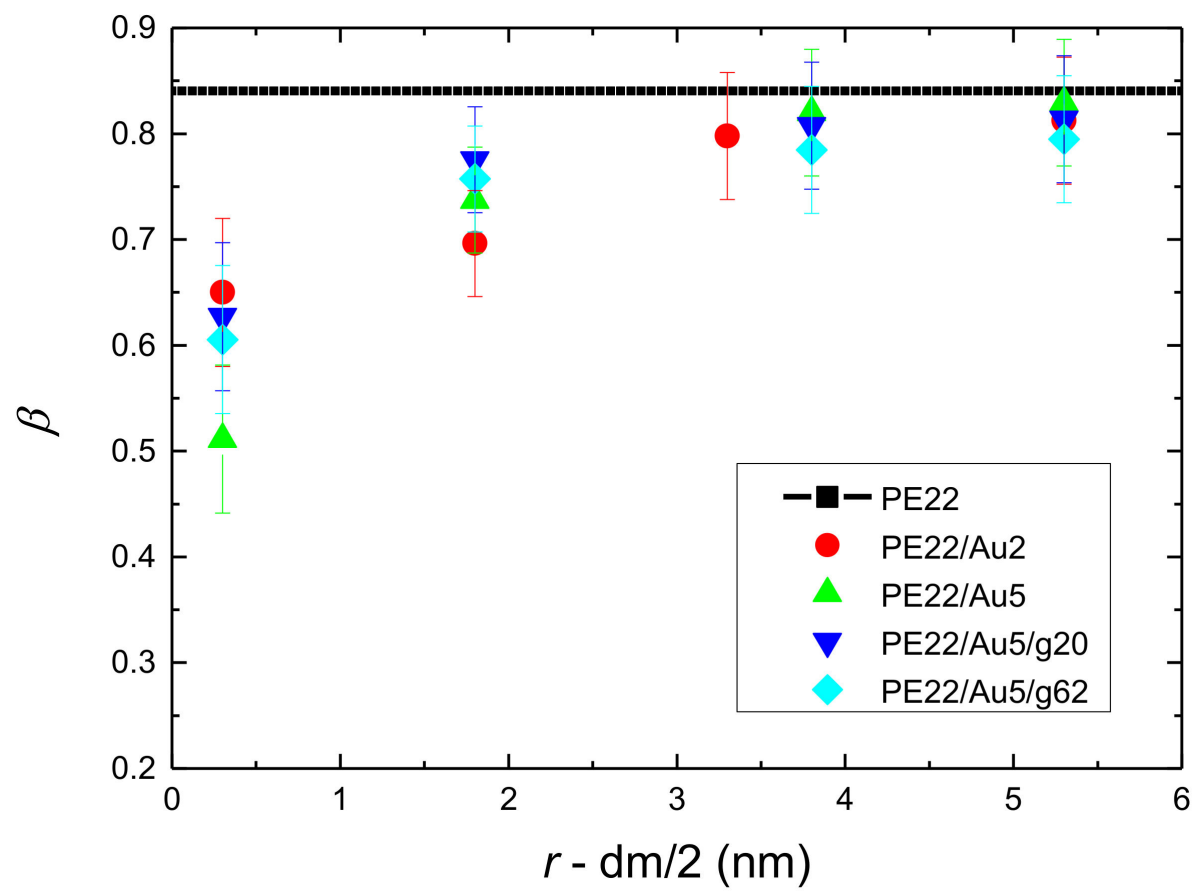

Figure A12. The stretch exponent $\beta$, as extracted from the fit with KWW functions, of $v^{\text {end-end }}$ characteristic vector based on $C_{\text {end-end }}(t)$ time autocorrelation as a function of $r$ (distance from the center of the Au NP) minus the half diameter of the NP, for all systems with PE matrices consisting of 22 mers per chain. Black lines represent $\beta$ values of bulk PE. 


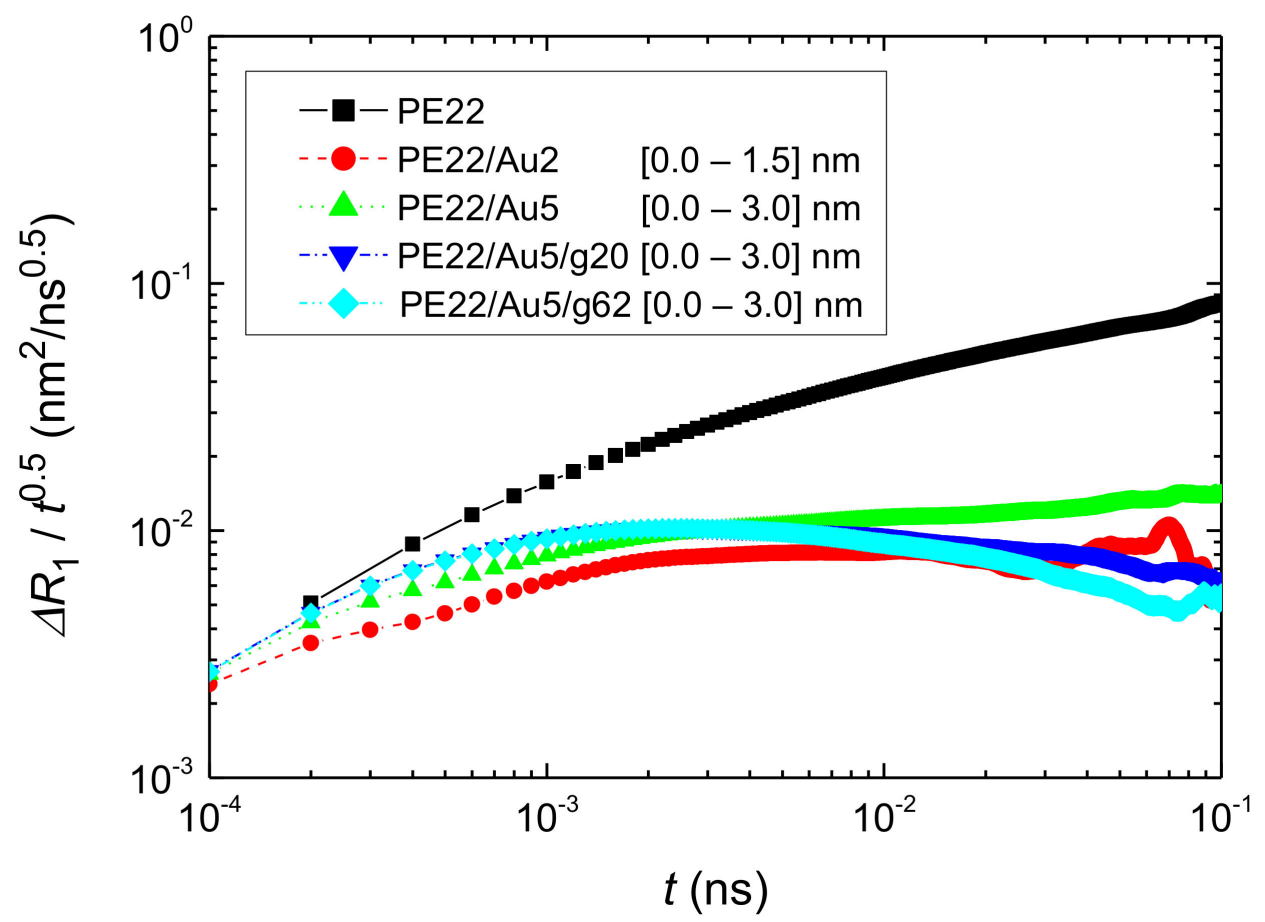

Figure A13. Segmental MSD of PE chains for the first adsorption spherical shell, $\Delta R_{1}$, scaled with $t^{0.5}$. Data for the PE22/Au2, PE22/Au5, PE22/Au5/g20 and PE22/Au5/g62 systems are shown, together with data for the bulk PE22 system.

\section{References}

1. Fu, S.-Y.; Sun, Z.; Huang, P.; Li, Y.-Q.; Hu, N. Some basic aspects of polymer nanocomposites: A critical review. Nano Mater. Sci. 2019, 1, 2-30. [CrossRef]

2. Alonso-Redondo, E.; Belliard, L.; Rolle, K.; Graczykowski, B.; Tremel, W.; Djafari-Rouhani, B.; Fytas, G. Robustness of elastic properties in polymer nanocomposite films examined over the full volume fraction range. Sci. Rep. 2018, 8, 16986. [CrossRef] [PubMed]

3. Bačová, P.; Rissanou, A.N.; Harmandaris, V.; Harmaris, V. Edge-Functionalized Graphene as a Nanofiller: Molecular Dynamics Simulation Study. Macromolecules 2015, 48, 9024-9038. [CrossRef]

4. Srivastava, S.; Schaefer, J.L.; Yang, Z.; Tu, Z.; Archer, L.A. 25th Anniversary Article: Polymer-Particle Composites: Phase Stability and Applications in Electrochemical Energy Storage. Adv. Mater. 2013, 26, 201-234. [CrossRef]

5. Kumar, S.K.; Krishnamoorti, R. Nanocomposites: Structure, Phase Behavior, and Properties. Annu. Rev. Chem. Biomol. Eng. 2010, 1, 37-58. [CrossRef] [PubMed]

6. Giannelis, E.P. Polymer Layered Silicate Nanocomposites. Adv. Mater. 1996, 8, 29-35. [CrossRef]

7. Balazs, A.C.; Emrick, T.; Russell, T.P. Nanoparticle Polymer Composites: Where Two Small Worlds Meet. Science 2006, 314, 1107-1110. [CrossRef]

8. Devi, J.M. Aggregation of thiol coated gold nanoparticles: A simulation study on the effect of polymer coverage density and solvent. Comput. Mater. Sci. 2014, 86, 174-179. [CrossRef]

9. Ma, J.-Z.; Liu, Y.-H.; Bao, Y.; Liu, J.-L.; Zhang, J. Research advances in polymer emulsion based on "core-shell" structure particle design. Adv. Colloid Interface Sci. 2013, 197, 118-131. [CrossRef]

10. Chrissopoulou, K.; Andrikopoulos, K.S.; Fotiadou, S.; Bollas, S.; Karageorgaki, C.; Christofilos, D.; Voyiatzis, G.A.; Anastasiadis, S.H. Crystallinity and Chain Conformation in PEO/Layered Silicate Nanocomposites. Macromolecules 2011, 44, 9710-9722. [CrossRef]

11. Corbierre, M.K.; Cameron, N.S.; Sutton, M.; Laaziri, K.; Lennox, R.B. Gold Nanoparticle/Polymer Nanocomposites: Dispersion of Nanoparticles as a Function of Capping Agent Molecular Weight and Grafting Density. Langmuir 2005, 21, 6063-6072. [CrossRef]

12. Kotelyanskii, M.; Theodorou, D.N. Simulation Methods for Polymers; Marcel Dekker Inc.: New York, NY, USA, 2004.

13. Dhoke, S.K.; Khanna, A. Study on electrochemical behavior of Nano-ZnO modified alkyd-based waterborne coatings. J. Appl. Polym. Sci. 2009, 113, 2232-2237. [CrossRef]

14. Laachachi, A.; Ruch, D.; Addiego, F.; Ferriol, M.; Cochez, M.; Cuesta, J.M.L. Effect of ZnO and organo-modified montmorillonite on thermal degradation of poly(methyl methacrylate) nanocomposites. Polym. Degrad. Stab. 2009, 94, 670-678. [CrossRef]

15. Dashtizadeh, A.; Abdouss, M.; Mahdavi, H.; Khorassani, M. Acrylic coatings exhibiting improved hardness, solvent resistance and glossiness by using silica nano-composites. Appl. Surf. Sci. 2011, 257, 2118-2125. [CrossRef] 
16. Che, X.-C.; Jin, Y.-Z.; Lee, Y.-S. Preparation of nano-TiO2/polyurethane emulsions via in situ RAFT polymerization. Prog. Org. Coatings 2010, 69, 534-538. [CrossRef]

17. Zhu, A.; Shi, Z.; Cai, A.; Zhao, F.; Liao, T. Synthesis of core-shell PMMA-SiO2 nanoparticles with suspension-dispersionpolymerization in an aqueous system and its effect on mechanical properties of PVC composites. Polym. Test. 2008, 27, 540-547. [CrossRef]

18. Wen, X.-F.; Li, M.-Z.; Pi, P.-H.; Chen, J.; Yang, Z.-R. Study of the physicochemical properties of silica powder and the stability of organic-inorganic hybrid emulsion in the presence of ethanol. Colloids Surf. A Physicochem. Eng. Asp. 2008, 327, 103-110. [CrossRef]

19. Kritikos, G.; Karatasos, K. Temperature dependence of dynamic and mechanical properties in poly(acrylic acid)/graphene oxide nanocomposites. Mater. Today Commun. 2017, 13, 359-366. [CrossRef]

20. España-Sánchez, B.L.; Ávila-Orta, C.A.; Padilla-Vaca, F.; Neira-Velázquez, M.G.; González-Morones, P.; Rodríguez-González, J.A.; Hernández-Hernández, E.; Rangel-Serrano, A.; Barriga-C, E.D.; Yate, L.; et al. Enhanced Antibacterial Activity of Melt Processed Poly(propylene) Ag and Cu Nanocomposites by Argon Plasma Treatment. Plasma Process. Polym. 2014, 11, 353-365. [CrossRef]

21. Babu, K.F.; Dhandapani, P.; Maruthamuthu, S.; Kulandainathan, M.A. One pot synthesis of polypyrrole silver nanocomposite on cotton fabrics for multifunctional property. Carbohydr. Polym. 2012, 90, 1557-1563. [CrossRef] [PubMed]

22. Palza, H. Antimicrobial Polymers with Metal Nanoparticles. Int. J. Mol. Sci. 2015, 16, 2099-2116. [CrossRef] [PubMed]

23. Nascimento, H.P.; Oliveira, M.D.; De Melo, C.P.; Silva, G.J.; Cordeiro, M.T.; Andrade, C.A. An impedimetric biosensor for detection of dengue serotype at picomolar concentration based on gold nanoparticles-polyaniline hybrid composites. Colloids Surfaces B Biointerfaces 2011, 86, 414-419. [CrossRef] [PubMed]

24. Pérez-López, A.M.; Rubio-Ruiz, B.; Sebastian, V.; Hamilton, L.; Adam, C.; Bray, T.L.; Irusta, S.; Brennan, P.M.; Lloyd-Jones, G.C.; Sieger, D.; et al. Gold-Triggered Uncaging Chemistry in Living Systems. Angew. Chem. Int. Ed. 2017, 56, 12548-12552. [CrossRef]

25. Shevach, M.; Fleischer, S.; Shapira, A.; Dvir, T. Gold Nanoparticle-Decellularized Matrix Hybrids for Cardiac Tissue Engineering. Nano Lett. 2014, 14, 5792-5796. [CrossRef]

26. Ribeiro, M.; Ferraz, M.P.; Monteiro, F.J.; Fernandes, M.H.; Beppu, M.M.; Mantione, D.; Sardon, H. Antibacterial silk fibroin/nanohydroxyapatite hydrogels with silver and gold nanoparticles for bone regeneration. Nanomed. Nanotechnol. Biol. Med. 2017, 13, 231-239. [CrossRef] [PubMed]

27. Li, Z.; Ye, E.; Lakshminarayanan, R.; Loh, X.J. Recent Advances of Using Hybrid Nanocarriers in Remotely Controlled Therapeutic Delivery. Small 2016, 12, 4782-4806. [CrossRef] [PubMed]

28. Bodelón, G.; Montes-García, V.; Fernández-López, C.; Pastoriza-Santos, I.; Pérez-Juste, J.; Liz-Marzán, L.M. Au@pNIPAM SERRS Tags for Multiplex Immunophenotyping Cellular Receptors and Imaging Tumor Cells. Small 2015, 11, 4149-4157. [CrossRef]

29. Xiao, C.; Wu, Q.; Chang, A.; Peng, Y.; Xu, W.; Wu, W. Responsive Au@polymer hybrid microgels for the simultaneous modulation and monitoring of Au-catalyzed chemical reaction. J. Mater. Chem. A 2014, 2, 9514-9523. [CrossRef]

30. Tang, F.; Ma, N.; Wang, X.; He, F.; Li, L. Hybrid conjugated polymer-Ag@PNIPAM fluorescent nanoparticles with metal-enhanced fluorescence. J. Mater. Chem. 2011, 21, 16943-16948. [CrossRef]

31. Zhang, J.; Ma, N.; Tang, F.; Cui, Q.; He, F.; Li, L. pH- and Glucose-Responsive Core-Shell Hybrid Nanoparticles with Controllable Metal-Enhanced Fluorescence Effects. ACS Appl. Mater. Interfaces 2012, 4, 1747-1751. [CrossRef]

32. Tamayo, L.; Palza, H.; Bejarano, J.; Zapata, P.A. 8-Polymer Composites with Metal Nanoparticles: Synthesis, Properties, and Applications. In Polymer Composites with Functionalized Nanoparticles; Pielichowski, K., Majka, T.M., Eds.; Elsevier: Amsterdam, The Netherlands, 2019; pp. 249-286.

33. Ding, Y.; Jiang, Z.; Saha, K.; Kim, C.S.; Kim, S.T.; Landis, R.F.; Rotello, V.M. Gold Nanoparticles for Nucleic Acid Delivery. Mol. Ther. 2014, 22, 1075-1083. [CrossRef] [PubMed]

34. Lai, C.-T.; Sun, W.; Palekar, R.U.; Thaxton, C.S.; Schatz, G.C. Molecular Dynamics Simulation and Experimental Studies of Gold Nanoparticle Templated HDL-like Nanoparticles for Cholesterol Metabolism Therapeutics. ACS Appl. Mater. Interfaces 2017, 9 , 1247-1254. [CrossRef]

35. Zhou, P.; Jia, S.; Pan, D.; Wang, L.; Gao, J.; Lu, J.; Shi, J.; Tang, Z.; Hua-Jie, L. Reversible Regulation of Catalytic Activity of Gold Nanoparticles with DNA Nanomachines. Sci. Rep. 2015, 5, srep14402. [CrossRef]

36. Teranishi, T. Fabrication and electronic properties of gold nanoparticle superlattices. Comptes Rendus Chim. 2003, 6, 979-987. [CrossRef]

37. Kim, Y.; Johnson, A.R.C.; Hupp, J.T. Gold Nanoparticle-Based Sensing of "Spectroscopically Silent" Heavy Metal Ions. Nano Lett. 2001, 1, 165-167. [CrossRef]

38. Boisselier, E.; Astruc, D. Gold nanoparticles in nanomedicine: Preparations, imaging, diagnostics, therapies and toxicity. Chem. Soc. Rev. 2009, 38, 1759-1782. [CrossRef] [PubMed]

39. Lal, S.; Link, S.; Halas, N.J. Nano-optics from sensing to waveguiding. Nat. Photon. 2007, 1, 641-648. [CrossRef]

40. Lu, Y.; Yin, Y.; Li, Z.-Y.; Xia, Y. Synthesis and Self-Assembly of Au@SiO2Core-Shell Colloids. Nano Lett. 2002, 2, 785-788. [CrossRef]

41. Zhang, R.-C.; Sun, D.; Zhang, R.; Lin, W.-F.; Macias-Montero, M.; Patel, J.; Askari, S.; McDonald, C.; Mariotti, D.; Maguire, P. Gold nanoparticle-polymer nanocomposites synthesized by room temperature atmospheric pressure plasma and their potential for fuel cell electrocatalytic application. Sci. Rep. 2017, 7, 46682. [CrossRef] [PubMed]

42. Wang, Z.; Tao, P.; Liu, Y.; Xu, H.; Ye, Q.; Hu, H.; Song, C.; Chen, Z.; Shang, W.; Deng, T. Rapid Charging of Thermal Energy Storage Materials through Plasmonic Heating. Sci. Rep. 2015, 4, srep06246. [CrossRef] [PubMed] 
43. Edwardson, T.G.W.; Lau, K.L.; Bousmail, D.; Serpell, C.J.; Sleiman, H.F. Transfer of molecular recognition information from DNA nanostructures to gold nanoparticles. Nat. Chem. 2016, 8, 162-170. [CrossRef]

44. Govorov, A.O.; Zhang, W.; Skeini, T.; Richardson, H.; Lee, J.; Kotov, N.A. Gold nanoparticle ensembles as heaters and actuators: Melting and collective plasmon resonances. Nanoscale Res. Lett. 2006, 1, 84-90. [CrossRef]

45. Anker, J.N.; Hall, W.P.; Lyandres, O.; Shah, N.C.; Zhao, J.; Van Duyne, R.P. Biosensing with plasmonic nanosensors. Nat. Mater. 2008, 7, 442-453. [CrossRef]

46. Shinde, S.K.; Kim, D.-Y.; Saratale, R.G.; Syed, A.; Ameen, F.; Kim, D.-Y. A Spectral Probe for Detection of Aluminum (III) Ions Using Surface Functionalized Gold Nanoparticles. Nanomaterials 2017, 7, 287. [CrossRef] [PubMed]

47. Alsawafta, M.; Badilescu, S.; Paneri, A.; Truong, V.-V.; Packirisamy, M. Gold-Poly(methyl methacrylate) Nanocomposite Films for Plasmonic Biosensing Applications. Polymers 2011, 3, 1833-1848. [CrossRef]

48. Betzer, O.; Meir, R.; Dreifuss, T.; Shamalov, K.; Motiei, M.; Shwartz, A.; Baranes, K.; Cohen, C.J.; Shraga-Heled, N.; Ofir, R.; et al. In-Vitro Optimization of Nanoparticle-Cell Labeling Protocols for In-vivo Cell Tracking Applications. Sci. Rep. 2015, 5, 15400. [CrossRef]

49. Liu, M.; Li, Q.; Liang, L.; Li, J.; Wang, K.; Li, J.; Lv, M.; Chen, N.; Song, H.; Lee, J.; et al. Real-time visualization of clustering and intracellular transport of gold nanoparticles by correlative imaging. Nat. Commun. 2017, 8, 15646. [CrossRef] [PubMed]

50. Park, J.H.; Lim, Y.T.; Park, O.O.; Kim, J.K.; Yu, J.-W.; Kim, Y.C. Polymer/Gold Nanoparticle Nanocomposite Light-Emitting Diodes: Enhancement of Electroluminescence Stability and Quantum Efficiency of Blue-Light-Emitting Polymers. Chem. Mater. 2004, 16, 688-692. [CrossRef]

51. Gupta, R.; Rai, B. Effect of Size and Surface Charge of Gold Nanoparticles on their Skin Permeability: A Molecular Dynamics Study. Sci. Rep. 2017, 7, srep45292. [CrossRef]

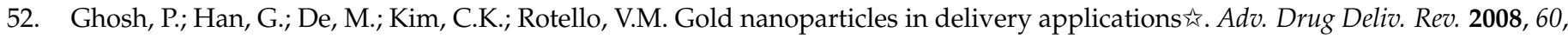
1307-1315. [CrossRef]

53. Remediakis, I.N.; López, N.; Nørskov, J.K. CO oxidation on gold nanoparticles: Theoretical studies. Appl. Catal. A Gen. 2005, 291, 13-20. [CrossRef]

54. Remediakis, I.N.; Lopez, N.; Nørskov, J.K. CO Oxidation on Rutile-Supported Au Nanoparticles. Angew. Chem. Int. Ed. 2005, 44, 1824-1826. [CrossRef]

55. Haruta, M. 4 Catalysis and applications of gold nanoparticles. In Studies in Surface Science and Catalysis; Anpo, M., Onaka, M., Yamashita, H., Eds.; Elsevier: Amsterdam, The Netherlands, 2003; pp. 31-38.

56. Von White, G.; Mohammed, F.S.; Kitchens, C.L. Small-Angle Neutron Scattering Investigation of Gold Nanoparticle Clustering and Ligand Structure Under Antisolvent Conditions. J. Phys. Chem. C 2011, 115, 18397-18405. [CrossRef]

57. Jia, H.; Grillo, I.; Titmuss, S. Small Angle Neutron Scattering Study of Polyelectrolyte Brushes Grafted to Well-Defined Gold Nanoparticle Interfaces. Langmuir 2010, 26, 7482-7488. [CrossRef]

58. Jang, J.D.; Jeon, S.-W.; Yoon, Y.-J.; Bang, J.; Han, Y.S.; Kim, T.-H. Self-assembly of gold nanoparticles in a block copolymer aggregate template driven by hydrophobic interactions. Polym. Chem. 2019, 10, 6269-6277. [CrossRef]

59. Coelho, S.C.; Pereira, M.D.C.; Rangel, M.; Ivanova, G. Structural characterization of functionalized gold nanoparticles for drug delivery in cancer therapy: A NMR based approach. Phys. Chem. Chem. Phys. 2015, 17, 18971-18979. [CrossRef] [PubMed]

60. Zhou, B.; Shen, M.; Banyai, I.; Shi, X. Structural characterization of PEGylated polyethylenimine-entrapped gold nanoparticles: An NMR study. Analyst 2016, 141, 5390-5397. [CrossRef] [PubMed]

61. Guo, C.; Yarger, J.L. Characterizing gold nanoparticles by NMR spectroscopy. Magn. Reson. Chem. 2018, 56, 1074-1082. [CrossRef] [PubMed]

62. Farea, M.O.; Abdelghany, A.M.; Oraby, A.H. Optical and dielectric characteristics of polyethylene oxide/sodium alginatemodified gold nanocomposites. RSC Adv. 2020, 10, 37621-37630. [CrossRef]

63. Mangal, R.; Srivastava, S.; Archer, L.A. Phase stability and dynamics of entangled polymer-nanoparticle composites. Nat. Commun. 2015, 6, 7198. [CrossRef] [PubMed]

64. Mijovic, J.; Lee, H.; Kenny, J.M.; Mays, J. Dynamics in Polymer-Silicate Nanocomposites As Studied by Dielectric Relaxation Spectroscopy and Dynamic Mechanical Spectroscopy. Macromolecules 2006, 39, 2172-2182. [CrossRef]

65. Papadimitriou, K.D.; Skountzos, E.N.; Gkermpoura, S.S.; Polyzos, I.; Mavrantzas, V.G.; Galiotis, C.; Tsitsilianis, C. Molecular Modeling Combined with Advanced Chemistry for the Rational Design of Efficient Graphene Dispersing Agents. ACS Macro Lett. 2015, 5, 24-29. [CrossRef]

66. Monti, S.; Carravetta, V.; Ågren, H. Decoration of gold nanoparticles with cysteine in solution: Reactive molecular dynamics simulations. Nanoscale 2016, 8, 12929-12938. [CrossRef] [PubMed]

67. Ndoro, T.V.M.; Voyiatzis, E.; Ghanbari, A.; Theodorou, D.N.; Boöhm, M.C.; Muüller-Plathe, F. Interface of Grafted and Ungrafted Silica Nanoparticles with a Polystyrene Matrix: Atomistic Molecular Dynamics Simulations. Macromolecules 2011, 44, 2316-2327. [CrossRef]

68. Allen, M.P.; Tildesley, D.J.; Banavar, J.R. Computer Simulation of Liquids. Phys. Today 1989, 42, 105-106. [CrossRef]

69. Doi, M.; Edwards, S.F. The Theory of Polymer Dynamics; Claredon: Oxford, UK, 1986.

70. Karatasos, K. Self-Association and Complexation of the Anti-Cancer Drug Doxorubicin with PEGylated Hyperbranched Polyesters in an Aqueous Environment. J. Phys. Chem. B 2013, 117, 2564-2575. [CrossRef] [PubMed] 
71. Karatrantos, A.V.; Clarke, N.; Kröger, M. Modeling of Polymer Structure and Conformations in Polymer Nanocomposites from Atomistic to Mesoscale: A Review. Polym. Rev. 2016, 56, 385-428. [CrossRef]

72. Harmandaris, V.; Angelopoulou, D.; Mavrantzas, V.G.; Theodorou, D.N. Atomistic molecular dynamics simulation of diffusion in binary liquid n-alkane mixtures. J. Chem. Phys. 2002, 116, 7656-7665. [CrossRef]

73. Milano, G.; Santangelo, G.; Ragone, F.; Cavallo, L.; Di Matteo, A. Gold Nanoparticle/Polymer Interfaces: All Atom Structures from Molecular Dynamics Simulations. J. Phys. Chem. C 2011, 115, 15154-15163. [CrossRef]

74. Rissanou, A.N.; Papananou, H.; Petrakis, V.S.; Doxastakis, M.; Andrikopoulos, K.S.; Voyiatzis, G.A.; Chrissopoulou, K.; Harmandaris, V.; Anastasiadis, S.H. Structural and Conformational Properties of Poly(ethylene oxide)/Silica Nanocomposites: Effect of Confinement. Macromolecules 2017, 50, 6273-6284. [CrossRef]

75. Fotiadou, S.; Karageorgaki, C.; Chrissopoulou, K.; Karatasos, K.; Tanis, I.; Tragoudaras, D.; Frick, B.; Anastasiadis, S.H. Structure and Dynamics of Hyperbranched Polymer/Layered Silicate Nanocomposites. Macromolecules 2013, 46, 2842-2855. [CrossRef]

76. Voyiatzis, E.; Rahimi, M.; Müller-Plathe, F.; Böhm, M.C. How Thick Is the Polymer Interphase in Nanocomposites? Probing It by Local Stress Anisotropy and Gas Solubility. Macromolecules 2014, 47, 7878-7889. [CrossRef]

77. Binder, K. Monte Carlo and Molecular Dynamics Simulations in Polymer Science; Oxford University Press: New York, NY, USA, 1995.

78. Vogiatzis, G.G.; Theodorou, D.N. Structure of Polymer Layers Grafted to Nanoparticles in Silica-Polystyrene Nanocomposites. Macromolecules 2013, 46, 4670-4683. [CrossRef]

79. Tsourtou, F.D.; Alexiadis, O.; Mavrantzas, V.G.; Kolonias, V.; Housos, E. Atomistic Monte Carlo and molecular dynamics simulation of the bulk phase self-assembly of semifluorinated alkanes. Chem. Eng. Sci. 2015, 121, 32-50. [CrossRef]

80. Ginzburg, V.V. Polymer-Grafted Nanoparticles in Polymer Melts: Modeling Using the Combined SCFT-DFT Approach. Macromolecules 2013, 46, 9798-9805. [CrossRef]

81. Posel, Z.; Posocco, P.; Lísal, M.; Fermeglia, M.; Pricl, S. Highly grafted polystyrene/polyvinylpyridine polymer gold nanoparticles in a good solvent: Effects of chain length and composition. Soft Matter 2016, 12, 3600-3611. [CrossRef]

82. Lin, J.; Zhang, H.; Morovati, V.; Dargazany, R. PEGylation on mixed monolayer gold nanoparticles: Effect of grafting density, chain length, and surface curvature. J. Colloid Interface Sci. 2017, 504, 325-333. [CrossRef]

83. Hagita, K.; Morita, H.; Doi, M.; Takano, H. Coarse-Grained Molecular Dynamics Simulation of Filled Polymer Nanocomposites under Uniaxial Elongation. Macromolecules 2016, 49, 1972-1983. [CrossRef]

84. Patra, T.K.; Singh, J.K. Coarse-grain molecular dynamics simulations of nanoparticle-polymer melt: Dispersion vs. agglomeration. J. Chem. Phys. 2013, 138, 144901. [CrossRef] [PubMed]

85. Quan, X.; Peng, C.; Dong, J.; Zhou, J. Structural properties of polymer-brush-grafted gold nanoparticles at the oil-water interface: Insights from coarse-grained simulations. Soft Matter 2016, 12, 3352-3359. [CrossRef]

86. Matsuda, T.; Smith, G.D.; Winkler, R.G.; Yoon, D.Y. Stochastic Dynamics Simulations of n-Alkane Melts Confined between Solid Surfaces: Influence of Surface Properties and Comparison with Scheutjens-Fleer Theory. Macromolecules 1995, 28, 165-173. [CrossRef]

87. Johnston, K.; Harmandaris, V. Hierarchical simulations of hybrid polymer-Solid materials. Soft Matter 2013, 9, 6696-6710. [CrossRef]

88. Johnston, K.; Harmandaris, V. Hierarchical Multiscale Modeling of Polymer-Solid Interfaces: Atomistic to CoarseGrained Description and Structural and Conformational Properties of Polystyrene-Gold Systems. Macromolecules 2013, 46, 5741-5750. [CrossRef]

89. Priestley, R.D.; Ellison, C.J.; Broadbelt, L.J.; Torkelson, J.M. Structural Relaxation of Polymer Glasses at Surfaces, Interfaces, and In Between. Science 2005, 309, 456-459. [CrossRef] [PubMed]

90. Harmandaris, V.A.; Daoulas, A.K.C.; Mavrantzas, V.G. Molecular Dynamics Simulation of a Polymer Melt/Solid Interface: Local Dynamics and Chain Mobility in a Thin Film of Polyethylene Melt Adsorbed on Graphite. Macromolecules 2005, 38, 5796-5809. [CrossRef]

91. Daoulas, K.C.; Harmandaris, V.A.; Mavrantzas, V.G. Detailed Atomistic Simulation of a Polymer Melt/Solid Interface: Structure, Density, and Conformation of a Thin Film of Polyethylene Melt Adsorbed on Graphite. Macromolecules 2005, 38, 5780-5795. [CrossRef]

92. Anastasiadis, S.H.; Karatasos, K.; Vlachos, G.; Manias, E.; Giannelis, E.P. Nanoscopic-Confinement Effects on Local Dynamics. Phys. Rev. Lett. 2000, 84, 915-918. [CrossRef] [PubMed]

93. Johnson, K.; Harmandaris, V. Properties of short polystyrene chains confined between two gold surfaces through a combined density functional theory and classical molecular dynamics approach. Soft Matter 2012, 8, 6320-6332. [CrossRef]

94. Mischler, C.; Baschnagel, J.; Dasgupta, S.; Binder, K. Structure and dynamics of thin polymer films: A case study with the bond-fluctuation model. Polymers 2002, 43, 467-476. [CrossRef]

95. Aoyagi, T.; Takimoto, J.-I.; Doi, M. Molecular dynamics study of polymer melt confined between walls. J. Chem. Phys. 2001, 115, 552-559. [CrossRef]

96. Rissanou, N.; Power, A.; Harmandaris, V. Structural and Dynamical Properties of Polyethylene/Graphene Nanocomposites through Molecular Dynamics Simulations. Polymers 2015, 7, 390-417. [CrossRef]

97. Hore, M.J.A.; Korley, L.T.J.; Kumar, S.K. Polymer-Grafted Nanoparticles. J. Appl. Phys. 2020, 128, 030401. [CrossRef]

98. Ge, T.; Grest, G.S.; Rubinstein, M. Nanorheology of Entangled Polymer Melts. Phys. Rev. Lett. 2018, 120, 057801. [CrossRef]

99. Peters, B.L.; Salerno, K.M.; Agrawal, A.; Perahia, D.; Grest, G.S. Coarse-Grained Modeling of Polyethylene Melts: Effect on Dynamics. J. Chem. Theory Comput. 2017, 13, 2890-2896. [CrossRef] 
100. Modica, K.J.; Martin, T.B.; Jayaraman, A. Effect of Polymer Architecture on the Structure and Interactions of Polymer Grafted Particles: Theory and Simulations. Macromolecules 2017, 50, 4854-4866. [CrossRef]

101. Martin, T.B.; Jayaraman, A. Using Theory and Simulations to Calculate Effective Interactions in Polymer Nanocomposites with Polymer-Grafted Nanoparticles. Macromolecules 2016, 49, 9684-9692. [CrossRef]

102. Ndoro, T.V.M.; Böhm, M.C.; Müller-Plathe, F. Interface and Interphase Dynamics of Polystyrene Chains near Grafted and Ungrafted Silica Nanoparticles. Macromolecules 2011, 45, 171-179. [CrossRef]

103. Sgouros, A.P.; Theodorou, D.N. Atomistic simulations of long-chain polyethylene melts flowing past gold surfaces: Structure and wall-slip. Mol. Phys. 2020, 118, e1706775. [CrossRef]

104. Jabbarzadeh, A.; Atkinson, J.; Tanner, R. Nanorheology of molecularly thin films of n-hexadecane in Couette shear flow by molecular dynamics simulation. J. NonNewtonian Fluid Mech. 1998, 77, 53-78. [CrossRef]

105. Berro, H.; Fillot, N.; Vergne, P.; Tokumasu, T.; Ohara, T.; Kikugawa, G. Energy dissipation in non-isothermal molecular dynamics simulations of confined liquids under shear. J. Chem. Phys. 2011, 135, 134708. [CrossRef]

106. Bright, K.; Malpass, B.W.; Packham, D.E. Adhesion of Polyethylene to Metals. Nat. Cell Biol. 1969, 223, 1360-1361. [CrossRef]

107. Suresh, B.; Maruthamuthu, S.; Kannan, M.; Chandramohan, A. Mechanical and surface properties of low-density polyethylene film modified by photo-oxidation. Polym. J. 2011, 43, 398-406. [CrossRef]

108. Song, H.; Li, B.; Lin, Q.-B.; Wu, H.-J.; Chen, Y. Migration of silver from nanosilver-polyethylene composite packaging into food simulants. Food Addit. Contam. Part A 2011, 28, 1-5. [CrossRef] [PubMed]

109. Rissanou, A.; Harmandaris, V. Dynamics of Polymer/Graphene Interfacial Systems. Soft Matter 2014, 10, 2876-2888. [CrossRef]

110. Hautman, J.; Klein, M.L. Simulation of a monolayer of alkyl thiol chains. J. Chem. Phys. 1989, 91, 4994-5001. [CrossRef]

111. Barmparis, G.D.; Honkala, K.; Remediakis, I.N. Thiolate adsorption on Au(hkl) and equilibrium shape of large thiolate-covered gold nanoparticles. J. Chem. Phys. 2013, 138, 64702. [CrossRef] [PubMed]

112. Barmparis, G.D.; Remediakis, I.N. Dependence on CO adsorption of the shapes of multifaceted gold nanoparticles: A density functional theory. Phys. Rev. B 2012, 86. [CrossRef]

113. Rissanou, A.N.; Harmandaris, V. Structural and Dynamical Properties of Polystyrene Thin Films Supported by Multiple Graphene Layers. Macromolecules 2015, 48, 2761-2772. [CrossRef]

114. Uz, M.; Bulmus, V.; Altinkaya, S.A. Effect of PEG Grafting Density and Hydrodynamic Volume on Gold Nanoparticle-Cell Interactions: An Investigation on Cell Cycle, Apoptosis, and DNA Damage. Langmuir 2016, 32, 5997-6009. [CrossRef]

115. Plimpton, S. Fast Parallel Algorithms for Short-Range Molecular Dynamics. J. Comput. Phys. 1995, 117, 1-19. [CrossRef]

116. Alexiadis, O.; Harmandaris, V.; Mavrantzas, V.G.; Site, L.D. Atomistic Simulation of Alkanethiol Self-Assembled Monolayers on Different Metal Surfaces via a Quantum, First-Principles Parametrization of the Sulfur-Metal Interaction. J. Phys. Chem. C 2007, 111, 6380-6391. [CrossRef]

117. Barmparis, G.D.; Lodziana, Z.; Lopez, N.; Remediakis, I.N. Nanoparticle shapes by using Wulff constructions and first-principles calculations. Beilstein J. Nanotechnol. 2015, 6, 361-368. [CrossRef] [PubMed]

118. Billinge, S.J.L.; Levin, I. The Problem with Determining Atomic Structure at the Nanoscale. Science 2007, 316, 561-565. [CrossRef]

119. Hadjisavvas, G.; Remediakis, I.N.; Kelires, P.C. Shape and faceting of Si nanocrystals embedded ina-SiO2: A Monte Carlo study. Phys. Rev. B 2006, 74, 165419. [CrossRef]

120. Herring, C. Some Theorems on the Free Energies of Crystal Surfaces. Phys. Rev. 1951, 82, 87-93. [CrossRef]

121. Vilé, G.; Baudouin, D.; Remediakis, I.N.; Copéret, C.; López, N.; Pérez-Ramírez, J. Silver Nanoparticles for Olefin Production: New Insights into the Mechanistic Description of Propyne Hydrogenation. ChemCatChem 2013, 5, 3750-3759. [CrossRef]

122. Li, Q.; Rellán-Piñeiro, M.; Almora-Barrios, N.; Garcia-Ratés, M.; Remediakis, I.N.; López, N. Shape control in concave metal nanoparticles by etching. Nanoscale 2017, 9, 13089-13094. [CrossRef] [PubMed]

123. Pearson, D.S.; Strate, G.V.; Von Meerwall, E.; Schilling, F.C. Viscosity and self-diffusion coefficient of linear polyethylene. Macromolecules 1987, 20, 1133-1141. [CrossRef]

124. Turzi, S.S. On the Cartesian definition of orientational order parameters. J. Math. Phys. 2011, 52, 053517. [CrossRef]

125. Sgouros, A.P.; Vogiatzis, G.G.; Megariotis, G.; Tzoumanekas, C.; Theodorou, D.N. Multiscale Simulations of Graphite-Capped Polyethylene Melts: Brownian Dynamics/Kinetic Monte Carlo Compared to Atomistic Calculations and Experiment. Macromolecules 2019, 52, 7503-7523. [CrossRef]

126. Gulde, M.; Rissanou, A.N.; Harmandaris, V.; Müller, M.; Schäfer, S.; Ropers, C. Dynamics and Structure of Monolayer Polymer Crystallites on Graphene. Nano Lett. 2016, 16, 6994-7000. [CrossRef]

127. Flory, P.J.; Volkenstein, M. Statistical mechanics of chain molecules. Biopolymers 1969, 8, 699-700. [CrossRef]

128. Williams, G.; Watts, D.C. Non-symmetrical dielectric relaxation behaviour arising from a simple empirical decay function. Trans. Faraday Soc. 1970, 66, 80-85. [CrossRef]

129. Harmandaris, V.A.; Mavrantzas, V.G.; Theodorou, D.N. Atomistic Molecular Dynamics Simulation of Polydisperse Linear Polyethylene Melts. Macromolecules 1998, 31, 7934-7943. [CrossRef]

130. Harmandaris, V.A.; Mavrantzas, V.G.; Theodorou, D.N.; Kröger, M.; Ramírez, J.; Öttinger, H.C.; Vlassopoulos, D. Crossover from the Rouse to the Entangled Polymer Melt Regime: Signals from Long, Detailed Atomistic Molecular Dynamics Simulations, Supported by Rheological Experiments. Macromolecules 2003, 36, 1376-1387. [CrossRef] 
131. Paul, W.; Smith, G.D.; Yoon, D.Y. Static and Dynamic Properties of an-C100H202Melt from Molecular Dynamics Simulations. Macromolecules 1997, 30, 7772-7780. [CrossRef]

132. Smith, G.D.; Bedrov, D. Dispersing Nanoparticles in a Polymer Matrix: Are Long, Dense Polymer Tethers Really Necessary? Langmuir 2009, 25, 11239-11243. [CrossRef] [PubMed] 